\title{
二维过渡金属硫族化合物纳米材料的制备与应用研究进展
}

\author{
林潇羽王璟* \\ (国防科技大学理学院 长沙 410073)
}

\begin{abstract}
摘要 二维过渡金属硫族化合物(TMDCs)纳米材料是一种新型的类石墨烯材料, 具有优异的电学、光学及催化特性. 简要介绍了 TMDCs 的晶体结构和电子特性; 详细综述了常用的制备方法, 主要包括机械剥离法、水(溶剂)热合成法、 化学气相合成法等, 并总结了各种方法的优缺点; 归纳了二维 TMDCs 在电子器件、光电器件、传感器、微波吸收、 储能和催化等方面的应用研究进展; 最后总结了该领域存在的问题, 展望了研究前景.
\end{abstract}

关键词 过渡金属硫族化合物; 纳米材料; 制备; 应用

\section{Research Progress on Preparation and Application of Two-Dimensional Transition Metal Dichalcogenides Nanomaterials}

\author{
Lin, Xiaoyu Wang, Jing* \\ (College of Science, National University of Defense Technology, Changsha, Hunan 410073)
}

\begin{abstract}
Two-dimensional (2D) materials have received great attentions in recent years, including BN, transition metal dichalcogenides, transition metal oxides and black phosphorus. Among them, graphene-like transition metal dichalcogenides (TMDCs), such as $\mathrm{MoS}_{2}, \mathrm{WS}_{2}, \mathrm{MoSe}_{2}, \mathrm{TiS}_{2}$, are emerging as key materials in electronics and chemical industry because of their excellent physical and chemical properties. Because of the quantum confinement and surface effects, the 2D nanomaterials exhibit completely different properties from their bulk, leading to a new field in material science and technology. The ability to prepare high quality and large scale TMDCs is the foundation for their practical applications. Until now, many methods have been employed to prepare various morphologies of TMDCs, including mechanical cleavage, intercalation-exfoliation, ultrasonic-assisted liquid-phase exfoliation, chemical vapor deposition and hydrothermal synthesis. In this paper, the authors introduce the crystal structures and electronic properties of TMDCs briefly. The dimension from bulk to single or few layers leads to changes of these nanomaterials, showing novel properties in electronic transfer rate, catalytic activity, etc. Then the top-down and bottom-up preparation methods are summarized, and the advantages and disadvantages of these methods are discussed. At present, the challenge is that there are no proper ways to prepare TMDCs in large scale with controlled thickness and general application. As every single material has its performance limitation, the hotpot in preparation lies in the hybridization with other materials to create functional composites, aiming to improve their electronic and optical properties for special devices, and the most commonly used components are graphene and other 2D materials. And the authors also introduce the research progress in applications systematically, with emphasis on electronic devices, optoelectronic devices, sensing platforms, energy storage devices and catalyst, showing a wide range of applications. In addition, the authors also give some perspectives on the challenges and prospects in this field.
\end{abstract}

Keywords transition metal dichalcogenides; nanomaterials; preparation; application

\section{1 引言}

在过去的十几年里, 人们在二维材料方面的研究取 得了巨大的进展. 2004 年, 英国曼切斯特大学的 Novoselov 等 ${ }^{[1]}$ 成功剥离出石墨烯, 开辟了材料研究的 新领域. 随后, 与石墨烯具有类似结构和性能的一种新 材料一一类石墨烯, 引起了物理、化学、材料和电子等 众多领域研究人员的广泛关注. 目前研究较多并取得一 定成果的类石墨烯二维材料有六方氮化硼 ${ }^{[2,3]}$ 、过渡金属 硫族化合物 ${ }^{[4]}$ 、过渡金属氧化物 ${ }^{[7]}$ 、过渡金属碳化物

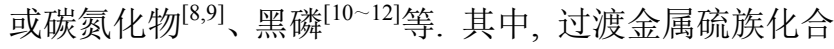
物(Transition Metal Dichalcogenides, TMDCs)作为一种 典型的层状材料，具有类似甚至优于石墨烯的特性，例 如 TMDCs 的带隙可调, 因此可用于场效应晶体管和逻 辑电路. 除此以外, TMDCs 在润滑、光电探测、传感、 储能、催化等方面都有广泛的应用.

本文综述了 TMDCs 的晶体结构和电子特性, 常用 制备方法及其在电子器件、光电器件、传感、微波吸收、 储能、催化等方面的应用, 以期为后续的研究理清思路.

* E-mail: jingwang@nudt.edu.cn; Tel.: 0731-84574786

Received June 27, 2017; published September 26, 2017.

Project supported by the National Natural Science Foundation of China (No. 21403298), the China Specialized Research Fund for the Doctoral Program of Higher Education (No. 20134307120015).

项目受国家自然科学基金(No. 21403298)和博士点基金(No. 20134307120015)资助. 


\section{2 过渡金属硫族化合物的晶体结构和电子特性}

TMDCs 有 40 多种类型 ${ }^{[13]}$, 基本化学式为 $\mathrm{MX}_{2}$, 其 中 $M$ 为过渡金属元素, $X$ 为硫族元素, 例如 $M_{0} S_{2} 、 S_{2}$ 、 $\mathrm{MoSe}_{2} 、 \mathrm{TiSe}_{2}$ 等. 与石墨类似, TMDCs 也是片层结构, 六方对称的晶胞在(001) 晶面方向进行堆叠, 层与层之 间靠范德华力相互作用, 平均层间距为 6 7 ; 与石墨 不同的是, TMDCs 片层呈三明治形状, 由两个六边形结 构的 $\mathrm{X}$ 原子层夹着一层 $\mathrm{M}$ 原子层形成一个 $\mathrm{MX}_{2}$ 分子层, 可用 “X-M-X” 表示, 如图 1 所示 ${ }^{[14]}$.

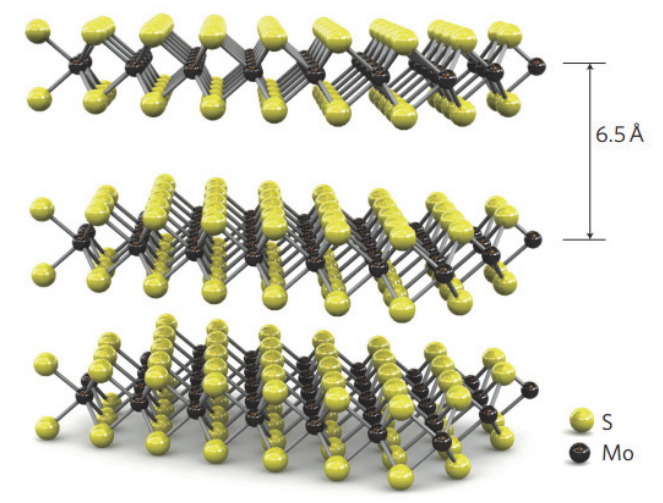

图 $1 \mathrm{MoS}_{2}$ 三维结构示意图 ${ }^{[14]}$

Figure 1 Three-dimensional representation of the structure of $\mathrm{MoS}_{2}{ }^{[14]}$

根据原子堆积方式和金属原子配位方式的不同, TMDCs 通常有三种晶体结构 ${ }^{[15]}$ : $1 \mathrm{~T} 、 2 \mathrm{H}$ 和 $3 \mathrm{R}$, 如图 2 所示, 不同晶体结构之间性质存在较大差异. 以 $\mathrm{MoS}_{2}$ 为例, 在自然状态下 $1 \mathrm{~T}-\mathrm{MoS}_{2}$ 是热力学非稳定相, $2 \mathrm{H}-\mathrm{MoS}_{2}$ 是热稳定相, 两者之间可以相互转化.

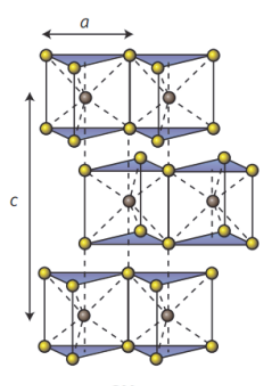

$2 \mathrm{H}$
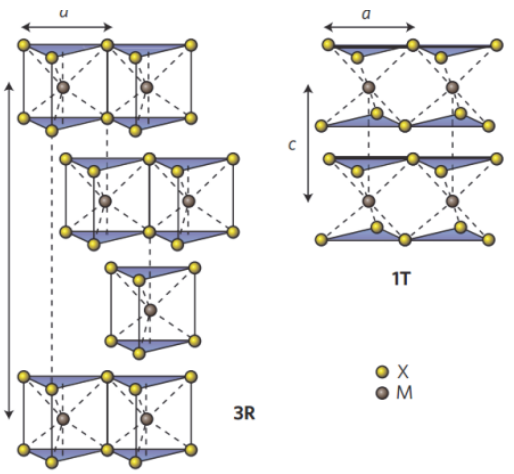

○ $\mathrm{X}$

图 $2 \mathrm{MoS}_{2}$ 的三种晶体结构: $2 \mathrm{H} 、 3 \mathrm{R}$ 和 $1 \mathrm{~T}^{[15]}$

Figure 2 The crystal structures of $\mathrm{MoS}_{2}: 2 \mathrm{H}, 3 \mathrm{R}$ and $1 \mathrm{~T}^{[15]}$

石墨烯是一种半金属材料, 而块体 TMDCs 展现出 多种电子特性. 根据金属原子的配位和氧化状态, 可以 分为金属、半金属、半导体和超导体, 块体 $\mathrm{MoS}_{2}$ 和 $\mathrm{WS}_{2}$ 属于半导体材料, $\mathrm{WTe}_{2}$ 和 $\mathrm{TiSe}_{2}$ 属于半金属, $\mathrm{NbS}_{2}$ 和 $\mathrm{VSe}_{2}$ 具有金属性质, $\mathrm{NbSe}_{2}$ 和 $\mathrm{TaS}_{2}$ 则表现出低温超导特 性 ${ }^{[16]}$.

与石墨烯相比, TMDCs 家族中半导体类材料最显 著的特点在于带隙可调. 以 $\mathrm{MoS}_{2}$ 为例, 块体 $\mathrm{MoS}_{2}$ 为间

接带隙半导体，带隙宽度为 $1.29 \mathrm{eV}$ ，随着层数的减少， $\mathrm{MoS}_{2}$ 带隙逐渐变大, 最后单层 $\mathrm{MoS}_{2}$ 发生间接带隙到直 接带隙的转变, 带隙宽度为 $1.8 \mathrm{eV}^{[14]}$. $\mathrm{WS}_{2}$ 和 $\mathrm{MoSe}_{2}$ 也 表现出相同的带隙特征 ${ }^{[17,18]}$. 在 $\mathrm{MoS}_{2}$ 的拉曼光谱中可 以观测到强烈的 $\mathrm{E}_{2 \mathrm{~g}}^{1}$ 和 $\mathrm{A}_{\mathrm{g}}^{1}$ 振动模式, 层数对频率、强度 以及两峰之间的宽度有着强烈的影响, 随着层数的增 加, $\mathrm{A}_{\mathrm{g}}^{1}$ 和 $\mathrm{E}_{2 \mathrm{~g}}^{1}$ 分别出现蓝移和红移的现象, 因此利用拉 曼光谱可以对 $\mathrm{MoS}_{2}$ 的层数进行分析 ${ }^{[19]}$. 由于量子限域 效应和表面效应，单层和少层 TMDCs 表现出不同于块 体材料的性质，例如单层 $\mathrm{MoS}_{2}$ 光致发光效应和产氢催 化能力的增强, 这些特性使其在电子器件、催化等领域 具有广阔的应用前景.

\section{3 过渡金属硫族化合物纳米材料的制备}

材料的高质量可控制备是发挥其性能的重要基础, 目前制备 TMDCs 的方法可以分为 “自上而下” 的剥离 法和 “自下而上” 的合成法.

\section{1 机械剥离法}

机械剥离法(Mechanical cleavage)是一种传统的制 备手段, 以其相对简便的操作和剥离程度高的特点成为 制备二维材料的成熟方法. 2004 年, Novoselov 等 ${ }^{[20]}$ 就利 用该法剥离出单层石墨烯. 随后, 又相继剥离出单层 $2 \mathrm{D}$ 材料 $\mathrm{BN} 、 \mathrm{MoS}_{2} 、 \mathrm{NbSe}_{2}$ 和 $\mathrm{Bi}_{2} \mathrm{Sr}_{2} \mathrm{CaCu}_{2} \mathrm{O}_{\mathrm{x}}$. Li 等 ${ }^{[21]}$ 也利用该方法得到了平均厚度为 $0.8 \mathrm{~nm}$ 的单层以及少 层 $\mathrm{MoS}_{2}$. 通过拉曼光谱分析, 单层 $\mathrm{MoS}_{2}$ 在 384 和 400 $\mathrm{cm}^{-1}$ 处有强烈的拉曼峰, 对应模 $\mathrm{E}_{2 \mathrm{~g}}^{1}$ 和 $\mathrm{A}_{\mathrm{g}}^{1}$. 机械剥离 法获得的样品结晶质量高、缺陷少、性质稳定, 并且与 块体材料具有相同的晶体结构, 非常适合于后续的性质 研究及单一电子器件的装配, 但是样品产量低, 一般用 于实验室制备, 难以大规模应用.

\section{2 超声液相剥离法}

超声液相剥离法 (Ultrasonic-assisted liquid-phase exfoliation) 是 2008 年由 Coleman 研究组报道的一种分离 石墨烯的方法 ${ }^{[22]}$, 随后他们利用该方法陆续剥离得到 $\mathrm{MoS}_{2} 、 \mathrm{NbSe}_{2} 、 \mathrm{TaSe}_{2} 、 \mathrm{MoTe}_{2} 、 \mathrm{~b}-\mathrm{BN}$ 和 $\mathrm{Bi}_{2} \mathrm{Te}_{3}$ 等 ${ }^{[23]}$. 这 种利用超声打破层间范德华力, 实现材料从本体剥离的 过程类似于聚合物在特殊溶液中的溶解 ${ }^{[24]}$, 可以用热 力学的混合焓理论 ${ }^{[22]}$ 以及分子层与溶剂分子之间的电 子传输作用来解释. 因此, 选择表面能与分子层间界面 能相匹配的溶剂，可以有效提高剥离效率.

常用的溶剂有三类: 有机溶剂、离子溶剂和水-表面 活性剂混合溶液. Coleman 等 ${ }^{[23]}$ 考察了多种溶剂对 $\mathrm{MoS}_{2}$ 和 $\mathrm{WS}_{2}$ 剥离效率的影响, 发现 $N$-2-甲基-吡咯烷酮 (NMP)的匹配效果最好, 可获得 $0.3 \mathrm{mg} / \mathrm{mL}$ 的 $\mathrm{MoS}_{2}$ 和 $0.15 \mathrm{mg} / \mathrm{mL}$ 的 $\mathrm{WS}_{2}$. 而后, Wang 等 ${ }^{[25]}$ 利用 $N$-甲基吡咯 烷酮(NMP)、 $N$-乙烯基吡咯烷酮(NVP)和环己基吡咯烷 酮(CHP)作为超声剥离介质, 其中 NMP 为介质, 所得产 
物中大约 $39 \%$ 的 $\mathrm{MoS}_{2}$ 纳米片厚度小于 $5 \mathrm{~nm}$. 此外, 在 有机溶剂中加入辅助剂可以改善剥离的效果. 例如在 NMP 或者环己酮中添加 $\mathrm{NaOH}$, 可以通过增大材料的层 间距来提高剥离效果.

另一方面, Smith 等 ${ }^{[26]}$ 直接采用水作为溶剂, 同时 加入胆酸钠作为表面活性剂以抑制产物团聚, 构成水表面活性剂体系得到了多种 TMDCs 和 BN 纳米材料 (图 3). 样品产量与表面活性剂浓度、初始 TMDCs 浓度 以及超声时间有关, 这为 TMDCs 纳米材料的批量制备 提供了参考.

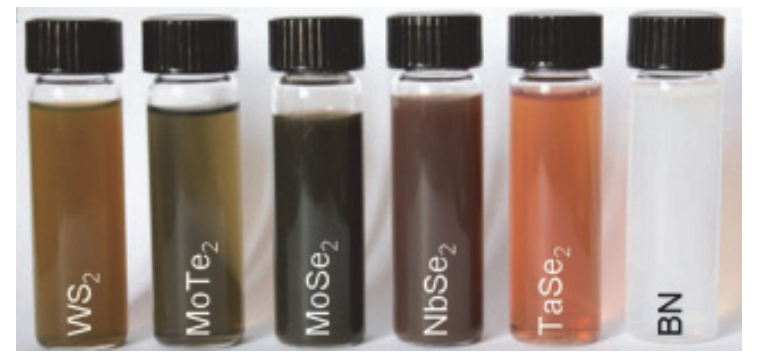

图 3 利用超声液相剥离法得到的二维 TMDCs 及 BN 分散液 ${ }^{[26]}$ Figure 3 Photograph of dispersions of 2D TMDCs and BN by ultrasonic-assisted liquid-phase exfoliation ${ }^{[26]}$

超声液相剥离法工艺简单, 可以大批量工业化生 产, 获得的产物可应用于纳米复合热电材料、超级电容 器和锂离子电池等方面, 尤其是最近有关在水相条件下 成功剥离 $\mathrm{MoS}_{2}$ 的文献报道更彰显了这一制备方法的工 业化应用前景. 但是该方法的剥离效果受到超声功率、 超声时间以及剥离介质等多种因素的影响, 并且产品厚 度难以控制、形貌单一。

\section{3 插层剥离法}

插层剥离法(Intercalation-Exfoliation)是通过在层间 插入小分子或者在片层上加上非共价连接的分子或聚 合物以获得层间化合物, 达到削减层间作用力和剥离层 状材料的目的. 插入分子的方法以电化学插入、气相插 入和液相插入为主, 插层试剂主要包括热稳定性差的硫 酸、硝酸、溴素和化学稳定性差的碱金属 Li、K、Cs、 $\mathrm{Rb}$ 等.

1986 年, Joensen 等 ${ }^{[27]}$ 首次采用锂离子插层法获得 了 $\mathrm{MoS}_{2}$. 其基本原理是先利用锂离子插层剂嵌入到 $\mathrm{MoS}_{2}$ 粉末中, 形成 $\mathrm{Li}_{x} \mathrm{MoS}_{2}(x \geqslant 1)$ 插层化合物, 再通过 插层化合物与质子性溶剂剧烈反应所产生出的大量 $\mathrm{H}_{2}$ 增大 $\mathrm{MoS}_{2}$ 的层间距, 进而得到多层甚至单层 $\mathrm{MoS}_{2}$. Matte 等 ${ }^{[28]}$ 采用相同方法, 将块体材料浸入丁基锂溶液 中 $100{ }^{\circ} \mathrm{C}$ 处理 $72 \mathrm{~h}$, 得到单层及少层 $\mathrm{MoS}_{2}$ 和 $\mathrm{WS}_{2} . \mathrm{Eda}$ 等 ${ }^{[29]}$ 进一步对 $\mathrm{MoS}_{2}$ 产物的晶体结构进行研究, 结果发 现: 室温下获得的产物为 $1 \mathrm{~T}$ 相和 $2 \mathrm{H}$ 相的混合物, 二者 各占约 $50 \%$. 随着退火处理温度的提高, 热力学非稳定 相 $1 \mathrm{~T}$ 逐渐消失, $300{ }^{\circ} \mathrm{C}$ 下热力学稳定相 $2 \mathrm{H}$ 可达到 $95 \%$. 为了改进化学锂离子插层法反应温度高、时间长等
缺点, Zeng 等 ${ }^{[30,31]}$ 运用电化学锂离子插层剥离法, 将层 状块体材料作为阴极, 锂箔作为阳极, 充电过程锂离子 插入层状材料层隙中, 放电过程锂与水反应生成 $\mathrm{H}_{2}$ 以 达到剥离目的. 利用该思路还可以制备多种 TMDCs $\left(\mathrm{MoS}_{2}, \mathrm{WS}_{2}, \mathrm{TiS}_{2}, \mathrm{WSe}_{2}, \mathrm{NbSe}_{2}\right.$ 等)、BN 和石墨烯纳米片. 这种方法可以在室温下进行, 反应时间较化学锂离子插 层法更短, 并且制备过程可通过放电曲线调控.

锂离子插层法剥离效率高、应用范围广，几乎可以 将所有的层状材料剥离至单层或者少层，但是该过程的 操作比较复杂, 可能会改变样品的电学性质, 限制了其 在电子器件方面的应用.

\section{4 水(溶剂)热合成法}

水热合成法(Hydrothermal synthesis)和溶剂热合成 法(Solvothermal synthesis)是采用水或者溶剂作为反应 介质在高温、高压环境中使通常难溶或不溶的物质溶解 并进行重结晶反应的方法. 反应温度范围一般在 100 $1000{ }^{\circ} \mathrm{C}$ 、压力范围 $1 \mathrm{MPa} \sim 1 \mathrm{GPa}$, 具有操作简单、污 染小、成本低廉以及纯度高的特点, 是一种非常具有潜 力的 TMDCs 合成方法.

研究人员很早就利用水热法合成出 $\mathrm{TMDCs}^{[32,33]}$. $\mathrm{He}$ 等 ${ }^{[34]}$ 以硫酸钛和硫化钠为反应物, 在 $200{ }^{\circ} \mathrm{C}$ 下水热 反应 $4 \mathrm{~h}$, 洗涤干燥后获得了 $\mathrm{TiS}_{2}$ 粉末. Zhang 等 ${ }^{[35]}$ 将硒 粉和钼酸钠溶解在水合肼中, 而后转入密闭的反应釜中 $200{ }^{\circ} \mathrm{C}$ 反应 $48 \mathrm{~h}$, 获得了纳米花状的 $\mathrm{MoSe}_{2}$. Chakravarty 等 ${ }^{[36]}$ 采用同样的思路, 将铇酸铵和单质硒 溶解在水合肼中，150 $170{ }^{\circ} \mathrm{C}$ 水热反应 $48 \mathrm{~h}$ 后得到微 米棒状 $\mathrm{WSe}_{2}$, 而采用铇酸为铇源时, 在相同的条件下 获得的产物为纳米颗粒状.

随着制备手段和制备条件的不断丰富，研究人员发 现各种反应条件都会影响合成过程, 其中表面活性剂的 加入可以有效地控制产物的形貌和结构. $\mathrm{Wu}$ 等 ${ }^{[37]}$ 采用 硫代铇酸铵为原料, 吡啶为溶剂, 三辛胺(TOA)为表面 活性剂, 制备出了空心球状的 $\mathrm{WS}_{2}$. 将空心球在氩气气 氛下退火，随着退火温度的升高 $(873 \sim 1123 \mathrm{~K}), \mathrm{WS}_{2}$ 晶 化程度加强, 但空心球结构被破坏. 随后, Cao 等 ${ }^{[38]}$ 利 用铇酸钠和硫嫝为原料, 以十六烷基三甲基溴化铵 (CTAB) 为表面活性剂制备出纳米花状的 $\mathrm{WS}_{2}$, 该样品 表现出良好的可见光吸收性能. 作者进一步研究发现, 反应时间对产物形态的影响远不如表面活性剂的种类 和用量，并提出了表面活性剂作用机理 ${ }^{[39]}$ (图 4).

水(溶剂)热法不仅可以合成单组分的纳米材料，还 可用于复合材料的制备. Huang 等 ${ }^{[40]}$ 开发了一种阳离子 表面活性剂辅助的水热合成法, 制备出类石墨烯 $\mathrm{MoS}_{2}$ / 石墨烯 $\left(\mathrm{GL}-\mathrm{MoS}_{2} / \mathrm{G}\right)$ 复合材料. Shelke 等 ${ }^{[41]}$ 采用水热法 制备出 $\mathrm{WS}_{2} / \mathrm{rGO}$ (reduced graphene oxide)纳米杂化材料 用于紫外光探测. $\mathrm{Li}$ 等 ${ }^{[42]}$ 利用超薄镍钴氢氧化物纳米片 和四硫代钼酸铵作为前驱体，通过在 $N, N$-二甲基甲酰胺 体系中引入水合肼, 实现了 $\mathrm{MoS}_{2}$ 从 $2 \mathrm{H}$ 和 $1 \mathrm{~T}$ 的混合相 


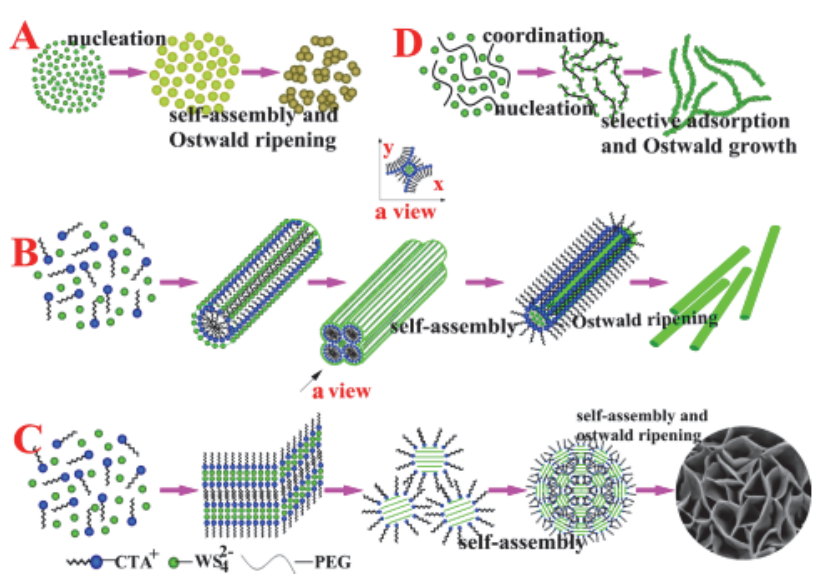

图 $4 \mathrm{WS}_{2}$ 合成过程中表面活性剂的作用机理示意图 ${ }^{[39]}$

Figure 4 Schematic illustration of the forming process of $\mathrm{WS}_{2}$ with different surfactants ${ }^{[39]}$

到纯 $1 \mathrm{~T}$ 相的完全转变, 并且调节了镍钴部分的结晶状 态, 最终形成了非晶态镍钴配合物和 $1 \mathrm{~T}$ 相 $\mathrm{MoS}_{2}$ 的复合 材料(图 5), 非晶态镍钴配合物起到稳定 $1 \mathrm{~T}$ 相的作用. 与传统的制备方法不同，水热法制备的复合材料实现了 分子层面的复合, 增强相与相、相与基体之间的能量和 物质流动，在催化、吸波等方面具有广泛的应用前景.

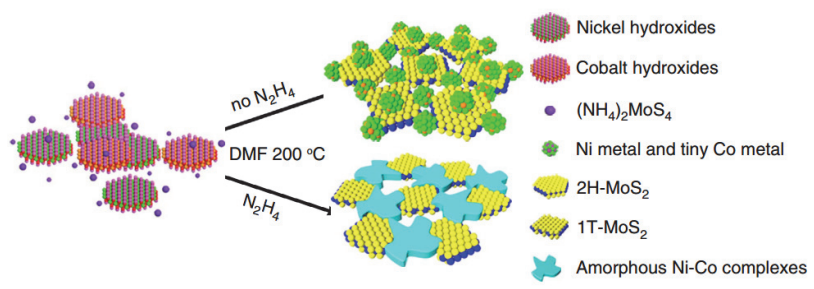

图 $5 \mathrm{Ni}-\mathrm{Co}$ 和 $1 \mathrm{~T}-\mathrm{MoS}_{2}$ 多孔杂化材料的制备 ${ }^{[42]}$

Figure 5 Schematic illustration of the formation of porous hybrid nanostructures combining amorphous Ni-Co complexes with 1T-MoS ${ }_{2}{ }^{[42]}$

总的说来, 水热法可以通过控制反应条件对产物进 行有效调控, 但受到反应温度所限, 产物晶体结构不够 完整，并且无法精确控制产物的厚度.

\section{5 化学气相沉积法}

化学气相沉积法(Chemical Vapor Deposition, CVD) 是工业中常用的制备无机纳米材料的方法, 主要包含两 种思路, 以 $\mathrm{MoS}_{2}$ 为例: (1)钼源先在祄底表面沉积, 而后 在高温下硫化或发生钿源热分解; (2)钿源在高温下升华 后和硫蒸气反应生成 $\mathrm{MoS}_{2}$, 沉积到祄底表面成核生长. CVD 可以大量制备厚度可控、大小可调和电学特性良 好的 $2 \mathrm{D}$ 纳米薄膜 ${ }^{[43]}$.

基于思路(1), Terrones 研究组 ${ }^{[44]}$ 以 $\mathrm{WO}_{3}$ 和 $\mathrm{S}$ 为前驱 体, 通过预沉积步骤, 将 $\mathrm{WO}_{x}$ 沉积在 $\mathrm{Si} / \mathrm{SiO}_{2}$ 基底上, 再 利用 $\mathrm{S}$ 蒸气直接硫化处理, 可以合成面积为 $1 \mathrm{~cm}^{2}$ 的单 层和少层 $\mathrm{WS}_{2}$ 薄膜. 同样的思路, 可以用 $\mathrm{MoO}_{3}$ 或 $\mathrm{Mo}$ 和 $\mathrm{S}$ 为前驱体, 制备 $\mathrm{MoS}_{2}$. 并且 $\mathrm{MoS}_{2}$ 薄膜的大小和厚 度分别由祄底的大小和 Mo 薄膜的厚度决定, 使得其合
成过程高度可控 ${ }^{[45,46]}$. 但该方法获得的 $\mathrm{MoS}_{2}$ 薄膜单晶 畴区极小 (大约 $20 \mathrm{~nm}$ ), 薄膜的电子迁移率只有 0.004 $0.04 \mathrm{~cm}^{2} /(\mathrm{V} \cdot \mathrm{s})$, 比机械剥离的 $\mathrm{MoS}_{2}$ 纳米片 $[0.1 \sim 10$ $\mathrm{cm}^{2} /(\mathrm{V} \cdot \mathrm{s})$ ]差了几个数量级, 缺陷多导致的低电子迁移 率和低电流通断比将限制材料的后续研究和应用. Laskar 等 ${ }^{[47]}$ 用蓝宝石祄底代替 $\mathrm{Si} / \mathrm{SiO}_{2}$ 基底, 先用电子束蒸 发沉积 $5 \mathrm{~nm}$ 厚的 Mo, 然后高温硫化处理, 获得了 (0001) 晶向的高质量单晶 $\mathrm{MoS}_{2}$ 薄膜. 并且随着生长温 度的提高, 薄膜的电学特性越来越接近于天然 $\mathrm{MoS}_{2}$, 基于所合成的 $\mathrm{MoS}_{2}$ 制备的场效应晶体管的电子迁移率 可以达到 $(12 \pm 2) \mathrm{cm}^{2} /(\mathrm{V} \cdot \mathrm{s})$.

基于思路(2), Najmaei 等 ${ }^{[48]}$ 报道了 $\mathrm{MoS}_{2}$ 的可控气相 合成方法, 制备出大面积、高结晶度的单层和少层 $\mathrm{MoS}_{2}$ 薄膜. 在该方法中, $\mathrm{MX}_{2}$ 的成核位点控制至关重要. 他 们发现二维 $\mathrm{MoS}_{2}$ 偏向于在基底边缘、污点或者粗䊅的 基底表面生长，因此通过基底表面图案化设计可以控制 成核位点, 不同位点的单晶相互连接得到厘米尺寸的薄 膜. Lee 等 ${ }^{[49]}$ 采用 APCVD (Ambient Pressure Chemical Vapor Deposition)的方法, 利用芳香族化合物二荎嵌苯3,4,9,10-四羧酸四钾盐(PTAS) 作为 “种子诱导剂” 促进 $\mathrm{MoS}_{2}$ 核的生长, 合成了结晶度高、缺陷少、形态均匀的 $\mathrm{MoS}_{2}$, 并且实现了祄底和 $\mathrm{MX}_{2}$ 薄膜的简易分离. 随后, 为了获得畴区尺寸可调的 $\mathrm{MoS}_{2}$, Shi 等 ${ }^{[50]}$ 以金䇴为生长 基底, 通过基底温度和载气组分的控制, 实现了 $\mathrm{MoS}_{2}$ 畴区尺寸从纳米到微米级的调控, 并获得边缘长度为 $81 \mu \mathrm{m}$ 的三角形单晶 $\mathrm{MoS}_{2}$. 将金箔上合成的纳米 $\mathrm{MoS}_{2}$ 直接用于电催化析氢，具有高效的产氢效率.

CVD 除了可以制备大面积薄膜, 还可以合成各种 精细结构, 该过程受到多种因素的影响. Wang 等 ${ }^{[51]}$ 利用 $\mathrm{MoO}_{3}$ 和 $\mathrm{Se}$ 粉末为前驱体制备了 $\mathrm{MoSe}_{2}$ 纳米片, 并研究 了 $\mathrm{Se} / \mathrm{Mo}$ 比对 $\mathrm{MoSe}_{2}$ 纳米片形态的影响. 研究发现, 当 $\mathrm{Se} / \mathrm{Mo}$ 比为 20、10 和 5 时, 产物形态为片状, 厚度分别 为 $32 、 10$ 和 $8 \mathrm{~nm}$; 当 $\mathrm{Se} / \mathrm{Mo}$ 比减小至 2 时, 产物为纳 米颗粒和纳米短棒的混合形态.

就目前而言, CVD 法可以用于合成高质量的 TMDCs, 但制备条件比较苛刻, 并且适用性相对较窄, 除了 $\mathrm{MoS}_{2} 、 \mathrm{WS}_{2} 、 \mathrm{MoSe}_{2}$ 等少数外 ${ }^{[52]}$, 一般难以采用该 方法. 如何拓展该法的普适性还有待进一步研究.

\section{6 胶体合成法}

胶体合成法(Colloidal synthesis)是在高沸点溶剂中 加入还原剂、表面修饰剂等, 将前驱物热解, 以此得到 尺寸均一的无机纳米晶. Mahler 等 ${ }^{[53]}$ 通过胶体合成法制 备了 $1 \mathrm{~T}$ 相 $\mathrm{WS}_{2}$ 纳米片, 当在合成过程中加入六甲基二 硅胺(HMDS)后, 导致 $\mathrm{WS}_{2}$ 形态和晶体结构剧烈变化, 实现 $1 \mathrm{~T}-\mathrm{WS}_{2}$ 到 $2 \mathrm{H}-\mathrm{WS}_{2}$ 的转变.

与前几种方法相比, 有关 TMDCs 胶体合成法的研 究较少, 但是该方法可以精确控制反应条件, 获得高结 晶度的纳米材料, 可运用于光催化、储能等方面 ${ }^{[4,55]}$. 


\section{4 过渡金属硫族化合物的应用研究}

\section{1 电子器件}

石墨烯以及类石墨烯材料由于其出众的电学和力 学性质, 一直是人们研究的热点 ${ }^{[56]} .2004$ 年, Novoselov 等 ${ }^{[1]}$ 就报道了第一个以石墨烯为基础的场效应晶体管 (Field Effect Transistor, FET), 表现出突出的双极性电场 效应. 但是石墨烯本身固有的 “ 0 ” 带隙效应, 严重限制 了 FET 的效率以及在逻辑电路方面的应用. 随后, 许多 研究致力于打开石墨烯的带隙, 但都以牺牲导电性 ${ }^{[57]}$ 或者消耗大量能量 ${ }^{[58]}$ 为代价. 寻求具备合适带隙的类 石墨烯材料成为新的解决方法. 在 TMDCs 中, 以 $\mathrm{WS}_{2}$ 和 $\mathrm{MoS}_{2}$ 为代表的半导体类材料, 具有合适的可调带隙. 这个特性使得 TMDCs 能够取代石墨烯, 被用于场效应 晶体管、逻辑电路等电子器件领域.

尽管 $\mathrm{MoS}_{2}$ 具有合适的带隙宽度, 但是单层 $\mathrm{MoS}_{2}$ 制成的背栅晶体管的电子迁移率仅有 $0.5 \sim 3 \mathrm{~cm}^{2} /$ $(\mathrm{V} \cdot \mathrm{s})^{[20]}$, 难以实际应用. 随后 Chen 等 ${ }^{[59]}$ 和 Konar 等 ${ }^{[60]}$ 的研究表明, 引入高介电常数的椓介质层, 可有效地提 升器件中载流子迁移率, 其原因在于高电介质可以通过 介电屏蔽作用抑制 $\mathrm{MoS}_{2}$ 的库伦杂质散射. Radisavljevic 等 ${ }^{[14]}$ 采用原子沉积技术制备了 $30 \mathrm{~nm}$ 厚的高介电常数 $\mathrm{HfO}_{2}$ 作为栅极介质, 采用微机械剥离法制备了 $6.5 \AA$ 厚 的 $\mathrm{MoS}_{2}$ 作为导电通道(图 6), 使得 $\mathrm{MoS}_{2}$ 电子器件的电 子迁移率从 $10 \mathrm{~cm}^{2} /(\mathrm{V} \cdot \mathrm{s})$ 提高至 $200 \mathrm{~cm}^{2} /(\mathrm{V} \cdot \mathrm{s})$, 接近改 性后的石墨烯纳米带 [电子迁移率为 $200 \mathrm{~cm}^{2} /(\mathrm{V} \cdot \mathrm{s})^{[61]}$ ] 以 及 $2 \mathrm{~nm}$ 厚的应变硅 [电子迁移率为 $250 \mathrm{~cm}^{2} /(\mathrm{V} \cdot \mathrm{s})^{[62]}$, 同 时电流开关比高达 $10^{8}$. 除了 $\mathrm{HfO}_{2}$ 外, 利用 $\mathrm{Al}_{2} \mathrm{O}_{3}$ 代替 $\mathrm{SiO}_{2}$ 作为介质绝缘层 ${ }^{[63]}$, 或者利用水溶性聚乙烯醇 (PVA)作为封盖层 ${ }^{[64]}$, 都可以提升 $\mathrm{MoS}_{2}$ 晶体管的电子 迁移率.

Yoon 等 ${ }^{[65]}$ 采用非平衡格林函数对 $\mathrm{MoS}_{2}$ 晶体管的性 能极限进行了研究. 结果表明, $\mathrm{MoS}_{2}$ 晶体管的电流通断 比可以达到 $10^{10}$, 且不受短沟道效应的影响, 适用于构 建低功率器件. 除了 $\mathrm{MoS}_{2}$ 晶体管外, 其他 TMDCs 晶体 管的研究也取得了一定的进展. Ovchinnikov 等 ${ }^{[6]]}$ 制备 了 $\mathrm{n}$ 型 $\mathrm{WS}_{2}$ 场效应晶体管, 其电子迁移率随温度降低而 增大, 当温度降低至 $83 \mathrm{~K}$ 左右时, 单层 $\mathrm{WS}_{2}$ 的迁移率最 高可以达到 $140 \mathrm{~cm}^{2} /(\mathrm{V} \cdot \mathrm{s})$, 而双层 $\mathrm{WS}_{2}$ 可以达到 300 $\mathrm{cm}^{2} /(\mathrm{V} \cdot \mathrm{s})$ 以上.

无论何种材料都存在性能极限, 随着二维材料的研 究不断深入, 利用石墨烯等材料的高电子迁移特性以及 TMDCs 的带隙可调特性制备新型复合材料, 以期构建 性能更加优越的电子器件成为必然趋势. Kwak 等 ${ }^{[67]}$ 研 究了 $\mathrm{MoS}_{2}$-石墨烯异质结的特性. 该异质结在 $\mathrm{MoS}_{2}$ 和 石墨烯之间形成了肖特基势垒, 而由栅极电压控制的肖 特基阻抗可以用来调节石墨烯上电子的传输特性. 在不 损耗石墨烯电子迁移能力的前提下, 该FET 的电流开关
比达到 100 , 可以初步实现逻辑开关功能. 之后, Srivastava 等 ${ }^{[68]}$ 对各种 FET 材料进行了总结, 虽然复合材 料能弥补单一组分的缺陷, 但是总体性能并没有达到预 期值, TMDCs 电子器件的性能还没有完全释放, 这个领 域仍有许多问题亟待解决.

逻辑电路也是一类重要的电子器件, 通过将简单的 单元集成在同一个芯片上，可以实现更加复杂多样的功 能. 在电子电路小型化、功能化、集成化不断发展的趋 势下, TMDCs 的能带结构和平面特性使其非常适于成 为纳米电子器件的基本构筑单元.

Radisavljevic 等 ${ }^{[69]}$ 制备了由两个 $\mathrm{MoS}_{2}$ 晶体管组成 的电子器件, 该电子器件可以实现信号放大和简单的逻 辑操作. 当输入逻辑信号 “ 0 ” (低电压输入), 可以转变 成逻辑信号 “ 1 ” (高电压输出); 也可以实现 NOR 门, 当 两个逻辑信号都为 “off” 时, 逻辑电路输出为 “ 1 ”, 否 则输出为 “ 0 ” (输出电压为 0 ), 由此可以推导出其他的 逻辑运算(AND、OR 等等). 对于逻辑电路, 为了使上一 个逻辑门的输出可以作为下一个逻辑门的输入, 其电压 增益需要高于 1 . Zou 等 ${ }^{[70]}$ 利用 $\mathrm{Y}_{2} \mathrm{O}_{3}$ 作为缓冲层, 研制 出 $\mathrm{HfO}_{2} / \mathrm{Y}_{2} \mathrm{O}_{3} / \mathrm{MoS}_{2}$ 顶栅晶体管. 将其作为反相器, 电压 增益可以达到 16 , 非常适合于逻辑器件集成.

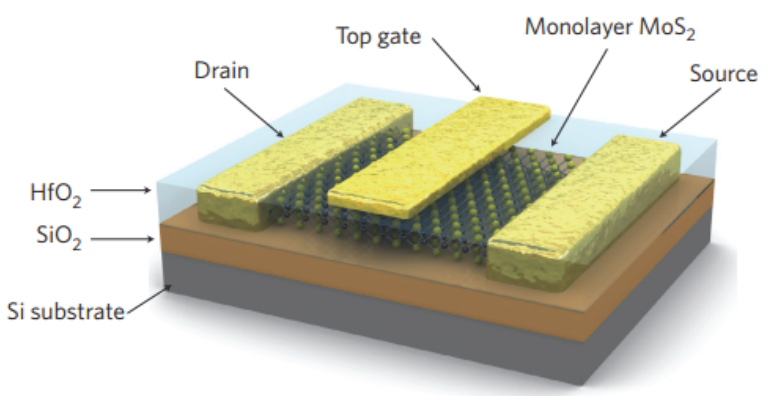

图 6 单层 $\mathrm{MoS}_{2}$ 场效应晶体管 ${ }^{[14]}$

Figure $6 \quad \mathrm{MoS}_{2}$ monolayer transistors ${ }^{[14]}$

\section{2 光电器件}

TMDCs 的光学性质和其能带结构有关, 而能带结 构又和材料的层数相关, 调控材料的层数即可改变其光 电特性. 并且, $\mathrm{MoS}_{2}$ 具有良好的光敏特性和响应速度, 因此可用于光电探测领域. Lee 等 ${ }^{[71]}$ 设计了一种顶栅结 构分别为单层、双层和三层 $\mathrm{MoS}_{2}$, 栅电极为透明导电玻 璃(ITO), 栅介质层为 $\mathrm{Al}_{2} \mathrm{O}_{3}$ 的光电晶体管. 结果显示, 三层 $\mathrm{MoS}_{2}$ (带隙 $1.35 \mathrm{eV}$ )光电晶体管适合于红光的探测, 单层(带隙 $1.82 \mathrm{eV}$ ) 和双层 $\mathrm{MoS}_{2}$ (带隙 $1.65 \mathrm{eV}$ ) 可以作为 绿光探测器, 如图 7 所示.

考虑到传统的光电探测器一般采用 $\mathrm{SiO}_{2} 、 \mathrm{HfO}_{2}$ 和 $\mathrm{Al}_{2} \mathrm{O}_{3}$ 作为椓介质, 如果要实现高灵敏度, 需要较高的 源极偏压和施加额外的栅极偏压. 为此 Wang 等 ${ }^{[2]}$ 研制 了铁电介质为栅极的 $\mathrm{MoS}_{2}$ 光电探测器, 其中三层 $\mathrm{MoS}_{2}$ 作为光敏半导体通道, 铁电材料聚偏二氟乙烯-三氟乙 
烯共聚物 [P(VDF-TrFE)] 作为顶栅介质, 利用 $\mathrm{P}(\mathrm{VDF}-\mathrm{TrFE})$ 的剩余极化来降低 $\mathrm{MoS}_{2}$ 半导体通道的暗 电流. 同时, 剩余极化能在局部产生 $109 \mathrm{~V} / \mathrm{m}$ 的强静电 场, 远远大于传统场效应晶体管的栅极偏压, 使得铁电 介质栅极 $\mathrm{MoS}_{2}$ 光电探测器具有超灵敏的响应. 该器件 对 $1 \mathrm{nW}$ 的激光功率表现出 $2570 \mathrm{~A} / \mathrm{W}$ 响应度, 探测率高 达 $2.2 \times 10^{12}$ Jones.

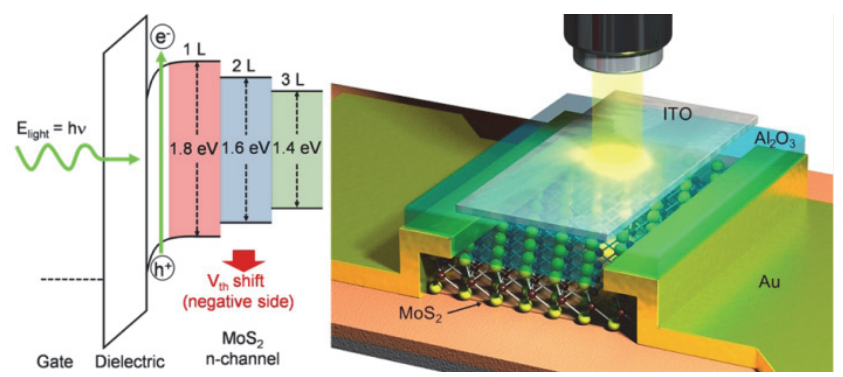

图 $7 \mathrm{MoS}_{2}-\mathrm{ITO}-\mathrm{Al}_{2} \mathrm{O}_{3}$ 光电晶体管 ${ }^{[71]}$

Figure 7 Schematic $3 \mathrm{D}$ view of $\mathrm{MoS}_{2}-\mathrm{ITO}-\mathrm{Al}_{2} \mathrm{O}_{3}$ phototransistor ${ }^{[71]}$

对于光电探测器而言, 光响应波段的宽窄也是衡量 其性能的重要指标. 由于光电探测器是基于光电效应, 可探测的光波段取决于材料的带隙, 而 $\mathrm{MoS}_{2}$ 等半导体 固有的带隙宽度 $(1.29 \sim 1.8 \mathrm{eV})$ 限制了其响应光谱区的 范围. 有研究发现, 在半导体的原子晶格上引入缺陷是 调整带隙以实现宽光谱响应的重要方法. Xie 等 ${ }^{[73]}$ 通过 控制 $\mathrm{MoS}_{2}$ 原子晶格的缺陷程度, 主要是硫空位缺陷, 使得多层 $\mathrm{MoS}_{2}$ 的带隙变窄, 实现了从 $445 \mathrm{~nm}$ (蓝光)到 $2717 \mathrm{~nm}$ (中红外)的超宽检测范围. 随着波长的增加, 虽 然响应度和探测率从 $50.7 \mathrm{~mA} / \mathrm{W}$ 和 $1.55 \times 10^{9}$ Jones 降低 至 $28.9 \mathrm{~mA} / \mathrm{W}$ 和 $0.88 \mathrm{Jones}$ (栅极偏压为 $10 \mathrm{~V}$ ), 但是与 传统的单层 $\mathrm{MoS}_{2}$ 探测器相比(入射光波长为 $550 \mathrm{~nm}$, 栅 极偏压为 $50 \mathrm{~V}$ 时, 光响应度 $\leqslant 7.5 \mathrm{~mA} / \mathrm{W})$, 仍具有较高 的光响应度.

尽管在 $\mathrm{MoS}_{2}$ 上引入硫空位等缺陷能拓展光电探测 器的响应范围, 但是缺陷的存在也影响了光电性能, 增 加了光响应时间 $(4 \sim 30 \mathrm{~s})$, 进而限制了其在光快速响应 方面的应用. Chang 等 ${ }^{[74]}$ 采用 CVD 法获得了单层 $\mathrm{MoS}_{2}$ 和 $\mathrm{MoSe}_{2}$, 两者具有相近的电子迁移率 $\left[17 \sim 23 \mathrm{~cm}^{2}\right.$ / $(\mathrm{V} \cdot \mathrm{s})$ ] 和电流通断比 $\left(10^{4} \sim 10^{5}\right)$, 但是 TEM 和光致发光 谱显示 $\mathrm{MoSe}_{2}$ 具有更少的缺陷, 而基于 $\mathrm{MoSe}_{2}$ 的光电晶 体管的光响应时间仅需 $25 \mathrm{~ms}$, 使得 $\mathrm{MoSe}_{2}$ 在光电子器 件方面有着独特的应用前景.

太阳能电池是利用光伏效应将太阳能转化成电能 的设备. TMDCs 具有可控带隙宽度, 可响应多种波段的 太阳光, 并且化学性质稳定, 是光伏电池的新型材料. Bernardi 等 ${ }^{[75]}$ 利用密度泛函理论 (Density Functional Theory, DFT)等方法计算了 $\mathrm{MoS}_{2} 、 \mathrm{MoSe}_{2}$ 和 $\mathrm{WS}_{2}$ 对太阳 光的吸收能力. 理论计算表明, 厚度为 $1 \mathrm{~nm}$ 的单层 TMDCs, 其光吸收率可以达到 $5 \% \sim 10 \%$, 远远大于相
同厚度 $\mathrm{Si}$ 和 GaAs. 同时研究人员构建了以 $\mathrm{MoS}_{2} /$ 石墨 烯为活性层材料的肖特基太阳能电池和基于 $\mathrm{MoS}_{2} / \mathrm{WS}_{2}$ 异质结的激子太阳能电池, 发现在厚度为 $1 \mathrm{~nm}$ 左右时, 能量转换效率(PCE)就可以达到 $1 \%$, 虽然比 $\mathrm{GaAs}$ 材料 小了 30 倍, 但所需厚度仅有 $\mathrm{GaAs}$ 材料的千分之一, 由 此展现出 TMDCs 在超薄光伏器件方面的巨大优势. 随 后, 大量的研究集中于提升 TMDCs 的能量转换效率. $\mathrm{Ma}$ 等 ${ }^{[76]}$ 利用紫外臭氧处理化学剥离得到的 $\mathrm{WS}_{2}$, 将其 作为有机太阳能电池的空穴传输层, 电池的能量转换效 率可以达到 $8.37 \%$. Tsai 等 ${ }^{[77]}$ 将 $\mathrm{MoS}_{2}$ 与 $\mathrm{p}-\mathrm{Si}$ 组成 II 型 异质结太阳能电池, 使能量转化效率达到 $5.23 \%$. 而后, Deng 等 ${ }^{[78]}$ 利用微电子和光子结构分析(AMPS-1D)软件 模拟分析 $\mathrm{n}-\mathrm{MoS}_{2} / \mathrm{p}-\mathrm{Si}$ 异质结太阳能电池, 并从理论上 进一步证明 $\mathrm{MoS}_{2}$ 是理想的太阳能电池材料, 其极限转 化效率可以达到 $19.0 \%$, 而实现高效率的关键是有效控 制 $\mathrm{Si}$ 和 $\mathrm{MoS}_{2} / \mathrm{Si}$ 界面上的缺陷水平.

除了光电探测器和太阳能电池, TMDCs 还可以作 为有机发光二极管 (OLEDs) 空穴注入材料和主体材 料 ${ }^{[79]}$. 另外, $\mathrm{MoS}_{2}$-聚乙烯吡咯烷酮(PVP)纳米复合材料 作为闪存型存储器的电学双稳态材料也有报道 ${ }^{[80]}$.

\section{3 传感器}

传统的半导体氧化物传感器虽然具有高灵敏度的 特点, 但是该类型传感器一般需要较高的工作温度 $\left(200 \sim 600{ }^{\circ} \mathrm{C}\right)^{[81]}$. 因此, 开发一种室温下的高灵敏传感 器成为研究的热点. 二维 TMDCs 具有比表面积大、表 面活性高以及高韧性等特性，可用于构建超高灵敏、快 速响应传感器. $\mathrm{Li}$ 等 ${ }^{[21]}$ 将机械剥离法制备得到的单层和 少层 $\mathrm{n}$ 型半导体 $\mathrm{MoS}_{2}$ 制成 FET 器件用于室温下 $\mathrm{NO}$ 气 体的检测, 随着 NO 的吸附量增多, FET 通道电阻增大、 电流减小, 以此反映 $\mathrm{NO}$ 气体量, 检出下限为 $0.8 \mathrm{ppm}$. 和机械剥离法不同, 用锂离子剥离法制备的纳米 $\mathrm{MoS}_{2}$ 性质有所改变. Zeng 等 ${ }^{[30]}$ 采取锂离子剥离法制备的 $\mathrm{MoS}_{2}$ 为 $\mathrm{p}$ 型半导体, 将其制成薄膜晶体管(Thin-film transistors, TFTs) 用于 NO 气体的检测, 其对 NO 的响应 与 $\mathrm{n}$ 型 $\mathrm{MoS}_{2}$ 的 FET 完全相反, 随吸附量增多, 通道电 阻减小、电流增大, 检出下限达到 190 ppt. 由此说明了 制备方法会改变材料的特征, 进而影响器件的性能和工 作原理.

除了 $\mathrm{NO}$ 气体, Late 等 ${ }^{[82]}$ 基于 $\mathrm{MoSe}_{2}$ 纳米片构建了 $\mathrm{NH}_{3}$ 气体传感器, 由于气体吸附导致的电子转移可以通 过拉曼光谱的位移来反映, 以此检测环境中 $\mathrm{NH}_{3}$ 量, 检 测下限可以达到 $50 \mathrm{ppm}$. $\mathrm{Li}^{\text {等 }}{ }^{[83]}$ 利用 $\mathrm{WS}_{2}$ 纳米片构建了 $\mathrm{NH}_{3}$ 气体传感器. 对于 $5 \mathrm{ppm}$ 的 $\mathrm{NH}_{3}$, 该传感器的响应 时间和恢复时间仅需 120 和 $150 \mathrm{~s}$, 并且改善了对甲醇、 乙醇和甲醛等干扰物质的选择性. 此外, 基于 $\mathrm{MoS}_{2}$ 的 $\mathrm{NO}_{2}$ 气体传感器 ${ }^{[84]}$ 和基于 $\mathrm{WS}_{2}$ 的湿度传感器 ${ }^{[85}$ 也有相 关报道. 这些传感器, 尤其是对有毒气体的检测, 在环 境监测方面可以发挥重要的作用. 
石墨烯、碳纳米管以及碳纳米粒子等在生物传感器 方面表现出良好的性能 ${ }^{[86 ~ 88]}$. 已有报道表明, TMDCs 比石墨烯荧光淬灭能力更强, 并且对单链 DNA 和双链 DNA 表现出差异性的亲和能力, 有望获得更加灵敏的 传感器. Zhu等 ${ }^{[89}$ 利用单层 $\mathrm{MoS}_{2}$ 纳米片构建传感平台来 检测核酸序列. 染料标记的单链 DNA 探针 (pDNA) 可以 通过核酸碱基和 $\mathrm{MoS}_{2}$ 纳米片之间的范德华力而吸附在 $\mathrm{MoS}_{2}$ 上, 然后染料的荧光淬灭, 而当 $\mathrm{pDNA}$ 与其互补的 靶 $\mathrm{DNA}(\mathrm{cDNA})$ 相互识别后, 因为 $\mathrm{MoS}_{2}$ 对单链 DNA(ssDNA)和双链 DNA(dsDNA)的亲和力不同, 染色 标记的探针脱落, 体系展现出很强的苂光特征, 所以可 以利用探针的苂光信号变化对 DNA 进行定量测定. 利 用 $\mathrm{Au}$ 修饰单层 $\mathrm{MoS}_{2}$ 后, DNA 与 $\mathrm{Au}$ 之间的 $\mathrm{Au}-\mathrm{SH}$ 键 可以进一步增强 $\mathrm{MoS}_{2}$ 对 DNA 的吸附, 从而显著提高传 感器的灵敏度和选择性 ${ }^{[90]}$. 利用 ssDNA 和 $\mathrm{MoS}_{2}$ 之间的 高亲和力以及蛋白质标记技术, 可以将蛋白质检测转化 为高灵敏度的 DNA 检测, Xiang 等 ${ }^{[91]}$ 以 $\mathrm{MoS}_{2}$ 纳米片构 建苂光生物传感平台来检测蛋白质. 以链需亲和素作为 检测样品, 其检测下限可以达到 $0.67 \mathrm{ng} / \mathrm{mL}$. 对于一些 重金属, 例如 $\mathrm{Hg}^{2+}$ 和 $\mathrm{Pd}^{2+}$, 利用 $\mathrm{Hg}^{2+}$ 与 $\mathrm{DNA}$ 探针上 $\mathrm{T}$ 碱基的 $\mathrm{T}-\mathrm{T}$ 错配反应形成 $\mathrm{T}-\mathrm{Hg}^{2+}-\mathrm{T}$ 结构, 可以使荧光基 团转化成游离态而展示很强的苂光. 对于长度短、同源 性高、低丰度的 MicroRNAs, 利用 $\mathrm{WS}_{2}$ 构建的传感器同 样可以有效检测 ${ }^{[92]}$.

电化学传感器是化学、生物检测的另一个重要思路. 前文介绍了一种染料标记的 DNA 检测方法, 鉴于其复 杂性, Wang 等 ${ }^{[93]}$ 构建了无标记的电化学 DNA 传感器, 利用甲基蓝作为电化学活性指示剂, 采用微分脉冲伏安 法测试整个 DNA 固定和杂交过程. 研究人员以 $t h$ 基因 片段作为目标 DNA，检测范围从 $1.0 \times 10^{-16} \mathrm{~mol} / \mathrm{L}$ 到 1.0 $\times 10^{-10} \mathrm{~mol} / \mathrm{L}$, 检测限为 $1.9 \times 10^{-17} \mathrm{~mol} / \mathrm{L}$, 显著低于之 前的报道. 电化学生物传感器将电化学的高灵敏度和生 物传感器的高特异性结合起来, 是一种更加优化的检测 手段. 盐酸克伦特罗 (CLB) 是一种人工合成的 $\beta$-2-肾上 腺素兴奋剂, 俗称 “瘦肉精”, 对人体有破坏心血管和 中枢神经的危害, 其检测工作一直受到人们的关注. Yang 等 ${ }^{[94]}$ 在玻璃碳电极上分层构建了 $\mathrm{MoS}_{2}$-Au-PEIhemin 复合材料制成电化学传感器(图 8), 通过各组分协 同作用使其对 CLB 具有优异的响应, 线性响应范围从 $10 \mathrm{ng} / \mathrm{mL}$ 至 $2 \mu \mathrm{g} / \mathrm{mL}$, 检测限为 $1.92 \mathrm{ng} / \mathrm{mL}$, 并且可对 真正猪肉样品进行检测.

\section{4 微波吸收}

随着电子器件的普及, 电磁污染成为一种新的环境 问题. 二维 TMDCs 独特的电性能和丰富的结构类型, 使其具备应用于微波吸收领域的潜力. 2015 年 Ning 等 ${ }^{[95]}$ 首次考察了超声剥离 $\mathrm{MoS}_{2}$ 纳米片的电磁参数, 并 与 $\mathrm{MoS}_{2}$ 块体进行对比, 发现前者的介电常数是后者的 两倍. 当吸收剂质量分数为 $60 \%$, 拟合厚度为 $2.4 \mathrm{~mm}$

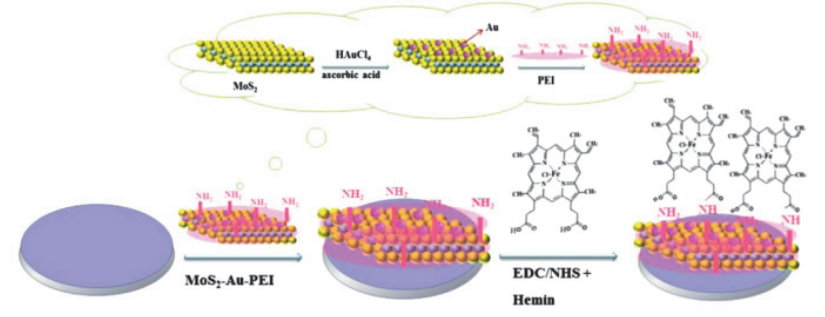

图 8 基于 $\mathrm{MoS}_{2}$-Au-PEI-hemin 的非酶传感器示意图 ${ }^{[94]}$

Figure 8 Schematic representation of the $\mathrm{MoS}_{2}$-Au-PEI-hemin based non-enzyme sensor ${ }^{[94]}$

时, 纳米片的最大反射损耗为 $-38.42 \mathrm{~dB}$, 是体相材料 的 4 倍, 有效带宽为 $4.1 \mathrm{GHz}(9.6 \sim 13.76 \mathrm{GHz})$, 与碳基 纳米材料的吸波性能相当. 分析认为由 Mo 和 $\mathrm{S}$ 的空位 所引入的缺陷偶极极化以及纳米片的高比表面积是导 致其高电磁损耗的主要原因. 随后, Liang 等 ${ }^{[96]}$ 首次考察 了水热合成 $\mathrm{MoS}_{2}$ 纳米片的微波吸收特性，当拟合厚度 为 $2.2 \mathrm{~mm}$ 时, 吸收剂的最大反射损耗为 $-47.8 \mathrm{~dB}$, 对 应 $12.8 \mathrm{GHz}$, 有效带宽 $4.5 \mathrm{GHz}(11 \sim 15.5 \mathrm{GHz})$. 值得 注意的是, 当厚度仅有 $1.9 \mathrm{~mm}$ 时, 有效带宽达 $5.2 \mathrm{GHz}$. 高导电性、较大的界面极化和高介电损耗是导致 $\mathrm{MoS}_{2}$ 纳米片展示优异电磁损耗特性的主要原因. 作者还考察 了水热反应温度对产物电磁参数的影响, 发现 $180{ }^{\circ} \mathrm{C}$ 制备的 $\mathrm{MoS}_{2}$ 其介电常数的实部和虚部高于其他样品.

除了片状的单一组分, 研究人员也开始将工作拓展 到其他形貌以及复合材料的微波吸收特性研究. Zhang 等 ${ }^{[97]}$ 利用水热法批量制备出由 $2 \mathrm{D}$ 纳米片堆积而成的 $3 \mathrm{D} \mathrm{MoS}_{2}$ 纳米微球, 并将其与聚偏氟乙烯(PVDF)复合, 研究其在 2 40 GHz 宽频率范围内的电磁波吸收性能, 结果发现: 当吸收剂质量分数为 $25 \%$, 拟合厚度为 2.5 $\mathrm{mm}$ 时, $\mathrm{MoS}_{2} / \mathrm{PVDF}$ 的最大反射损耗为 $-26.11 \mathrm{~dB}$, 峰值 在 $11.36 \mathrm{GHz}$, 有效带宽 $3.44 \mathrm{GHz}(9.92 \sim 13.36 \mathrm{GHz})$. 改变填料比例，可以有效调节吸波性能：在 $18 \sim 40 \mathrm{GHz}$ 波段，吸收剂质量分数为 $30 \%$, 拟合厚度为 $1.5 \mathrm{~mm}$ 时, 最大反射损耗为 $-27.47 \mathrm{~dB}$, 峰值对应 $18.47 \mathrm{GHz}$; 将吸 收剂质量分数降为 $20 \%$ 时，匹配厚度将显著增大，厚度 为 $3.5 \mathrm{~mm}$ 时, 最大反射损耗一 $32.67 \mathrm{~dB}$, 峰值在 28.93 GHz. 最后作者还对材料的微波吸收机制进行了探讨, 认为各种偏振、破坏性干扰理论、多次反射均是材料吸 收微波的主要机制. Ding 等 ${ }^{[98]}$ 首次制备并考察了 $\mathrm{rGO} / \mathrm{MoS}_{2} 3 \mathrm{D}$ 复合结构的吸波性能，匹配厚度为 2.5 $\mathrm{mm}$ 时, 其有效带宽为 $5.92 \mathrm{GHz}$, 最大反射损耗为 -31 $\mathrm{dB}$. 文中作者还将自己的工作与他人进行了对比, 结果 表明 $\mathrm{rGO}-\mathrm{MoS}_{2}$ 复合材料在轻质吸波材料领域的潜在应 用. Zhang 等 ${ }^{[99]}$ 先用溶剂热法制备了 $\mathrm{NiS}_{2}$ 纳米微球, 并 以此为核，在其表面生长了 $\mathrm{MoS}_{2}$ 纳米片，构成 $\mathrm{NiS}_{2} @ \mathrm{MoS}_{2}$ 的核壳结构. 当吸收剂质量分数为 $20 \%$, 拟 合厚度为 $2.2 \mathrm{~mm}$ 时, $\mathrm{NiS}_{2} @ \mathrm{MoS}_{2} / \mathrm{PVDF}$ 的最大反射损 耗为 $-41.05 \mathrm{~dB}$, 峰值对应 $12.08 \mathrm{GHz}$, 有效带宽 4.40 $\mathrm{GHz}(10.16 \sim 14.56 \mathrm{GHz})$. 与单组分吸波材料 $\mathrm{NiS}_{2} /$ 
PVDF ( - 12.47 dB) 和 $\mathrm{MoS}_{2} / \mathrm{PVDF}(-15.40 \mathrm{~dB}$ )相比, 吸 波性能明显提升. 研究发现, 虽然 $\mathrm{NiS}_{2}$ 和 $\mathrm{MoS}_{2}$ 都具有 较高的复介电常数, 为电介质损耗型吸波材料, 但是当 吸收剂质量分数为 $30 \%$ 时, $\mathrm{MoS}_{2}$ 的加入反而可以降低 $\mathrm{NiS}_{2} @ \mathrm{MoS}_{2}$ 的复介电常数, 以趋向阻抗匹配. 同时, 材 料之间的协同作用、多次反射等均有可能影响复合材料 的吸波特性. 改变复合吸收剂组分, 比如选用磁损耗型 吸收剂, 相信对改善阻抗匹配效果、提高材料的吸波性 能非常有利.

\section{5 储能器件}

锂离子电池(Lithium-ion batteries, LIBs)是一种新型 化学电源, 理论能量密度可以达到 $410 \mathrm{Wh} / \mathrm{kg}$, 是镍镉 电池的 $2 \sim 3$ 倍, 输出电压能达到铅蓄电池的 2 倍左 右 ${ }^{[100]}$. 但是金属锂电极在电化学循环过程中, 由于电 极表面不均匀沉淀, 易形成锂枝晶和不均匀溶出, 而形 成失去电化学活性的 “死锂” 。迄今为止, 碳基、硅基、 锡基以及合金基材料都被提出作为负极材料，尤其是用 嵌锂化合物代替金属锂负极促使了 LIBs 的广泛应用, 但是这些材料在脱嵌锂的过程中会产生较大的体积膨 胀, 大大影响电池的循环性能. TMDCs 的层状结构有利 于锂离子在电极中快速扩散, 同时少层 TMDCs 因为堆 积结构非常松散, 在嵌锂前后可以极大地适应结构变 化, 体积膨胀率低, 被认为是理想的 LIBs 负极材料.

2005 年, Guo 等 ${ }^{[101]}$ 利用水热法合成直径约为 200 $\mathrm{nm}$ 的 $\mathrm{MoS}_{2}$ 纳米微球作为 LIBs 的负极材料, 首次放电 比容量达到了 $1272 \mathrm{~mA} \cdot \mathrm{h} \cdot \mathrm{g}^{-1}$, 是石墨电极的 $3 \sim 4$ 倍. 对于直接用做负极材料的 TMDCs, 通常难以同时获得 高容量和良好的循环特性. 所以在循环 20 次以后, 比容 量仅剩下 $400 \mathrm{~mA} \cdot \mathrm{h} \cdot \mathrm{g}^{-1}$. Du 等 ${ }^{[102]}$ 利用锂离子化学剥离 法得到了 $\mathrm{MoS}_{2}$ 纳米片, 再通过水热处理对剥离的 $\mathrm{MoS}_{2}$ 进行改性, 得到重新堆积的 $\mathrm{MoS}_{2}$. 与原始 $\mathrm{MoS}_{2}$ 相比, 重堆积 $\mathrm{MoS}_{2}$ 的晶胞沿 $\mathrm{c}$ 轴方向拓宽了 $0.235 \AA$, 为锂离 子进入 $\mathrm{S}$ 原子层提供更大的空间. 将重堆积的 $\mathrm{MoS}_{2}$ 作 为 LIBs 负极材料, 在 50 次循环后比容量仍能达到 750 $\mathrm{mA} \cdot \mathrm{h} \cdot \mathrm{g}^{-1}$, 而原始 $\mathrm{MoS}_{2}$ 已经降低至 $226 \mathrm{~mA} \cdot \mathrm{h} \cdot \mathrm{g}^{-1}$. Wang 等 ${ }^{[103]}$ 直接将单层 $M_{0}$ 组装成三维管状结构, 独 特的空心和孔隙结构非常适合用于构建 LIBs 负极材料, 放电比容量和循环性能都优于未经处理的 $\mathrm{MoS}_{2}$ 纳米片. Zhou 等 ${ }^{[104]}$ 利用(3-颈基丙基)三甲氧基硅烷(MPS)对水 热法制备的 $\mathrm{WS}_{2}$ 进行硫化处理, 以修复 $\mathrm{WS}_{2}$ 的硫空位 和去除残留的氧原子. 在锂离子存储性能方面, 当电流 密度为 $0.8 \mathrm{~A} \cdot \mathrm{g}^{-1}$ 时, 硫化处理和未处理 $\mathrm{WS}_{2}$ 的初始比 容量分别为 857.7 和 $746.9 \mathrm{~mA} \cdot \mathrm{h} \cdot \mathrm{g}^{-1}, 50$ 次循环后降为 566.8 和 $381.7 \mathrm{~mA} \cdot \mathrm{h} \cdot \mathrm{g}^{-1}$. 硫化处理使得 $\mathrm{WS}_{2}$ 的锂离子存 储性能提升了 $48.4 \%$. 之后, 作者还试验了 $\mathrm{SnS}_{2}$, 并得 到相同的效果, 说明硫化处理可以成为一种通用改性方 法.
但是，无论是原始还是改性后的 TMDCs，导电性 能差一直是制约其发展的重要因素. 大量的研究表明, 在 LIBs 中添加少量的石墨烯就可以改善 LIBs 的电化学 性能 ${ }^{[105,106]}$. 于是, 将 TMDCs 与高导电性材料石墨烯复 合成为改善 TMDCs 电极的重要思路. Chang 等 ${ }^{[107]}$ 以半 胱氨酸(L-cysteine)作为模板和硫源, 再加上钼酸钠和氧 化石墨烯, 利用水热法制备了 $\mathrm{MoS}_{2}$ /石墨烯复合材料, 当 $\mathrm{Mo}$ 和 $\mathrm{C}$ 的物质的量比为 $1: 2$, 电流密度为 $100 \mathrm{~mA}$ $\mathrm{g}^{-1}$ 时, 该体系的比容量可以达到 $1100 \mathrm{~mA} \cdot \mathrm{h} \cdot \mathrm{g}^{-1}$, 在循 环 100 次后比容量基本不变. 当电流密度达到 1000 $\mathrm{mA} \cdot \mathrm{h} \cdot \mathrm{g}^{-1}$ 时, 比容量依旧可以高达 $900 \mathrm{~mA} \cdot \mathrm{h} \cdot \mathrm{g}^{-1}$, 体现 了 $\mathrm{MoS}_{2}$ /石墨烯作为 LIBs 负极材料的巨大潜力. Luo 等 ${ }^{[108]}$ 制备了 $\mathrm{MoSe}_{2} / \mathrm{rGO}$ 杂化材料，其中石墨烯不仅作 为 $\mathrm{MoSe}_{2}$ 成核生长的位点, 而且是 LIBs 的电子传输通 道. 当电流密度为 $100 \mathrm{~mA} \cdot \mathrm{h} \cdot \mathrm{g}^{-1}$ 时, 该体系的首次放电 比容量可以达到 $1399 \mathrm{~mA} \cdot \mathrm{h} \cdot \mathrm{g}^{-1}$, 可逆比容量为 1001 $\mathrm{mA} \cdot \mathrm{h} \cdot \mathrm{g}^{-1}$. 循环 100 次后, 可逆比容量仍可以达到 715 $\mathrm{mA} \cdot \mathrm{h} \cdot \mathrm{g}^{-1}$ ，展现出优异的储能特性，同时该体系在 2000 $\mathrm{mA} \cdot \mathrm{g}^{-1}$ 高电流密度下依旧具有高容量和良好的恢复能 力, 展现出优良的倍率性能. Wang 等 ${ }^{[109]}$ 在制备 $\mathrm{MoS}_{2} /$ rGO 时, 利用表面活性剂乙醇对 $\mathrm{MoS}_{2}$ 的形态进行控制, 获得纳米片状 $\mathrm{MoS}_{2}$. 当电流密度为 $100 \mathrm{~mA} \cdot \mathrm{h} \cdot \mathrm{g}^{-1}$ 时, 该体系的首次充放电比容量分别为 1454 和 $1902 \mathrm{~mA} \cdot \mathrm{h} \cdot$ $\mathrm{g}^{-1}$, 库伦效率可以达到 $76.45 \%$.

超级电容器是一种功率密度高、循环寿命长的新型 储能元件. 根据电荷存储的机理不同, 超级电容器主要 可以分为双电层电容器(Electrical Double Layer Capacitor)、法拉第噟电容器(Pseudocapacitor)和混合型电容器 (Hybrid capacitor). $\mathrm{MoS}_{2}$ 纳米材料具有巨大的比表面积 和层间空间, 并且 Mo 原子在氧化还原过程中拥有多种 价态, 因此, 以 $\mathrm{MoS}_{2}$ 作为电极材料兼具双电层和法拉 第赝电容器的特点 ${ }^{[110,111]}$. 另有研究表明, $\mathrm{MoS}_{2}$ 作为电 极材料时, 比氧化物具有更快的电子传输能力 ${ }^{[112]}$, 比 石墨烯有更高的理论比电容 ${ }^{[113]}$, 展现出优异的性能.

Wang 等 ${ }^{[114]}$ 制备了 $\mathrm{MoS}_{2} /$ 聚苯胺(PANI)纳米复合材 料, 以此为电极材料制备的超级电容器, 其比电容可以 达到 $390 \mathrm{~F} \cdot \mathrm{g}^{-1}$, 高于一般的碳材料电极. 虽然低于 $\mathrm{RuO}_{2} 、 \mathrm{MnO}_{2}$ 等金属氧化物，但是制备成本低、循环稳 定性高, $\mathrm{MoS}_{2} / \mathrm{PANI}-38\left(\mathrm{MoS}_{2}\right.$ 质量分数为 $\left.38 \%\right)$ 在 1000 次循环后仍能保持 $80 \%$ 的比电容. 并且, $\mathrm{MoS}_{2}$ 和 PANI 的比例对电容器的储能机理也有影响: 当 $\mathrm{MoS}_{2}$ 质量分 数为 $8 \%$ 时, 电容器的储能机理以双电层为主, 当 $\mathrm{MoS}_{2}$ 质量分数为 $24 \%$ 和 $38 \%$ 时, 由于 $\mathrm{MoS}_{2}$ 的团聚, 电容器 的储能机理为法拉第噟电容. 目前, 影响双电层形成的 关键问题是复合材料中 $\mathrm{MoS}_{2}$ 的团聚. 如果能够解决上 述问题, 将有望进一步提升此类复合材料的储能性能. 


\section{6 催化}

氢能被认为是 21 世纪最清洁的能源, 是代替化石 燃料的最佳选择之一. 目前, 制取氢气的方法包括热分 解法、太阳能光解法以及水电解法. 在水电解法中, 催 化剂的加入能显著降低电化学反应的过电位, 使得电解 水具有非常高的制氢效率. 寻求高效、价格低廉的催化 剂用于析氢反应(Hydrogen Evolution Reaction, HER)是 该领域的研究重点.

一直以来, 氢原子在催化剂表面的吉布斯自由能 $\Delta G_{\mathrm{H}^{*}}$ 被用于反映 HER 电催化剂的本征活性, 交换电流 密度和 $\Delta G_{\mathrm{H}^{*}}$ 之间的关系可以用 “火山模型” 描述, 图 9 中 $\mathrm{Pt} 、 \mathrm{Rh} 、 \mathrm{Re}$ 等贵金属位于火山峰处, 具有最高的交 换电流密度和接近于 0 的氢原子吸附能. 虽然 $\mathrm{Pt}$ 等贵金 属作为 HER 催化剂具有最高的活性, 但是昂贵的价格 限制了其大规模运用. 研究人员一直在寻找可替代的催 化剂.

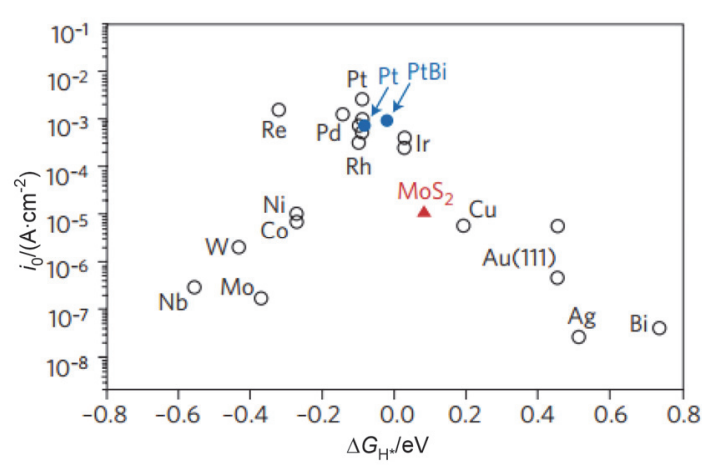

图 9 交换电流密度-氢吸附自由能的 “火山” 模型[115]

Figure 9 Volcano plot of the exchange current density vs calculated standard free energy of adsorption of hydrogen ${ }^{[115]}$

2005 年, Hinnemann 等 ${ }^{[116]}$ 开创性地利用 DFT 分析 了 $\mathrm{MoS}_{2}$ 的氢原子吸附能, 大约为 $+0.08 \mathrm{eV}$, 与 $\mathrm{Pt}$ 非常 接近, 也位于 “火山峰” 附近. 之后许多研究表明, $\mathrm{MoSe}_{2} 、 \mathrm{WSe}_{2}$ 等 TMDCs 也具有很高的 HER 催化活 性 ${ }^{[17 \sim 119]}$.

许多理论和实验研究认为纳米 TMDCs 的催化活性 位位于边缘位点上那些暴露的 X (Mo, W 等) 原子, 而大 量的表面位是催化㤢性的 ${ }^{[16]}$. Chorkendorff 课题组 ${ }^{[120]}$ 在 研究 $\mathrm{MoS}_{2}$ 的边缘催化位点时发现：在反应过程中, $\mathrm{MoS}_{2}$ 边缘位点只有四分之一结合了氢原子, 因此, 同 一时刻只有四分之一的位点能释放 $\mathrm{H}_{2}$, 而 $\mathrm{Pt}(111)$ 的氢 原子覆盖度大约为 $1 \mathrm{ML}^{[121]}$. 因此, 通过调节材料边缘 的电子结构来增强氢原子吸附能, 或者通过修饰纳米结 构、改变电子传输结构, 提高单位面积的催化位点数量, 就能达到提升催化性能的目的.

利用碳材料做基底, 不仅可以提高 HER 催化剂的 电子传输特性, 而且催化剂在碳基上的高度分散可以获 得更多的活性位点. $\mathrm{Li}$ 等 ${ }^{[117]}$ 利用溶剂热法合成 $\mathrm{MoS}_{2} / \mathrm{rGO}$ 杂化材料用于 HER 研究. $\mathrm{MoS}_{2}$ 纳米粒在 rGO
层上高度分散充分暴露了 $\mathrm{MoS}_{2}$ 的催化位点, 其过电位 仅有 $0.1 \mathrm{~V}(\mathrm{Pt}$ 为 $0 \mathrm{~V}), \mathrm{Tafel}$ 斜率为 $41 \mathrm{mV} \cdot \mathrm{dec}^{-1}$, 催化活 性高于单一的 $\mathrm{MoS}_{2}$ 催化剂, 与贵金属催化剂 Pt 接近(31 $\mathrm{mV} \cdot \mathrm{dec}^{-1}$ ). 但不同于 $\mathrm{Pt}$ 的 Volmer-Tafel 机理, 该催化过 程符合 Volmer-Heyrovsky 机理, $\mathrm{H}_{2}$ 的电化学解吸过程是 反应的限速步骤. $\mathrm{Xu}$ 等 ${ }^{[122]}$ 也合成 $3 \mathrm{D} \mathrm{MoS}_{2}-\mathrm{rGO}$ 气凝胶, 其过电位和 Tafel 斜率只有 $105 \mathrm{mV}$ 和 $51 \mathrm{mV} \cdot \mathrm{dec}^{-1}$, 交 换电流密度可以达到 $3.28 \times 10^{-5} \mathrm{~A} \cdot \mathrm{cm}^{-2}$, 与单一 $\mathrm{MoS}_{2}$ 相比(120 mV 和 $\left.69 \mathrm{mV} \cdot \mathrm{dec}^{-1}\right)$, 催化性能有所提升.

TMDCs 具有多种微观结构和形态, 例如纳米颗粒、 纳米线和纳米片等, 而不同的形态将影响边缘催化位点 数. Wang 等 ${ }^{[123]}$ 采用溶剂热法合成了石墨烯状的 $\mathrm{WSe}_{2}$ 纳米片, 其独特的多孔纳米结构提供了更多的边缘催化 位点, 初始过电位为 $150 \mathrm{mV}$, Tafel 斜率 $78 \mathrm{mV} \cdot \mathrm{dec}^{-1}$. Chen 等 ${ }^{[124]}$ 构建了 $\mathrm{MoO}_{3}-\mathrm{MoS}_{2}$ 的核-壳结构纳米线, 其 中 $\mathrm{MoS}_{2}$ 壳起到催化 HER 和防护的作用, $\mathrm{MoO}_{3}$ 核提供了 纵向的高比表面积模板和电荷传输通道. 在电流密度为 $10 \mathrm{~mA} \cdot \mathrm{cm}^{-2}$ 时, 过电位为 $250 \mathrm{mV}$, Tafel 斜率为 $50 \sim 60$ $\mathrm{mV} \cdot \mathrm{dec}^{-1}$. Yang 等 ${ }^{[125]}$ 利用 $\mathrm{MoSe}_{2}$ 纳米片分别构建了 $\mathrm{MoSe}_{2}$ 和硫掺杂的 $\mathrm{MoSe}_{2-x}$ 纳米多层结构, 高催化位点 数和良好的导电性使其具有优异的 HER 催化性能. 而 后, Ding 等 ${ }^{[126]}$ 利用 $\mathrm{MoS}_{2}$ 纳米片构建了片层取向更加有 序的 3D 柱状分层结构, 不仅减少了片层团聚的情况, 而且使得片层充分暴露活性位点, 其 Tafel 斜率低至 39 $\mathrm{mV} \cdot \mathrm{dec}^{-1}$.

TMDCs 的多种晶体结构之间也存在非常大的差异, 例如 $2 \mathrm{H}-\mathrm{MoS}_{2}$ 和 $2 \mathrm{H}-\mathrm{WS}_{2}$ 相表现出半导体性质, 而将其 转化成金属性 $1 \mathrm{~T}-\mathrm{MoS}_{2}$ 和 $1 \mathrm{~T}-\mathrm{WS}_{2}$ 相可以提升 HER 催化 活性. Lukowski 等 ${ }^{[127]}$ 先在石墨基底上合成了纳米花状 的 $2 \mathrm{H}-\mathrm{MoS}_{2}$, 而后通过锂离子插层的方法实现了 $2 \mathrm{H}-\mathrm{MoS}_{2}$ 向 $1 \mathrm{~T}-\mathrm{MoS}_{2}$ 的转变. 在电流密度为 $10 \mathrm{~mA}$ $\mathrm{cm}^{-2}$ 时, $2 \mathrm{H}-\mathrm{MoS}_{2}$ 需要施加 $320 \mathrm{mV}$ 的过电位; 而在电 流密度为 $200 \mathrm{~mA} \cdot \mathrm{cm}^{-2}$ 时, $1 \mathrm{~T}-\mathrm{MoS}_{2}$ 只需要施加 $400 \mathrm{mV}$ 的过电位, 表现出更高的 HER 催化活性. Voiry 等 ${ }^{[128]}$ 对 $\mathrm{MoS}_{2}$ 的 $1 \mathrm{~T}$ 和 $2 \mathrm{H}$ 相的催化效能差异进行研究, 结果发 现 $1 \mathrm{~T}$ 和 $2 \mathrm{H}$ 相的催化机理没有本质上的不同，限制 $2 \mathrm{H}$ 相催化性能的主要原因是高电阻妨碍了电子传递. 在 $2 \mathrm{H}-\mathrm{MoS}_{2}$ 中掺入单壁碳纳米管以降低其过电位, 可以提 升 $2 \mathrm{H}-\mathrm{MoS}_{2}$ 的催化性能. 随后, Wang 等 ${ }^{[129]}$ 制备了一种 $1 \mathrm{~T} / 2 \mathrm{H}$ 多相催化剂, $1 \mathrm{~T}$ 相为 HER 提供更多的活性位点和 更优良的导电性能, 而 $2 \mathrm{H}$ 相的存在有利于稳定 $1 \mathrm{~T}$ 亚稳 定相，当电流密度为 $10 \mathrm{~mA} \cdot \mathrm{cm}^{-2}$ 时，其 Tafel 斜率为 46 $\mathrm{mV} \cdot \mathrm{dec}^{-1}$, 过电位为 $234 \mathrm{mV}$. Li 等 ${ }^{[42]}$ 将非晶态镍钴配合 物和 $1 \mathrm{~T}$ 相 $\mathrm{MoS}_{2}$ 复合, 并将其用于析氢和析氧反应中, 在 $10 \mathrm{~mA} \cdot \mathrm{cm}^{-2}$ 处对应的过电位分别为 70 和 $235 \mathrm{mV}$, Tafel 斜率为 38.1 和 $45.7 \mathrm{mV} \cdot \mathrm{dec}^{-1}$.

除了催化 HER 反应, TMDCs 还能用于催化加氢脱 硫反应 ${ }^{[130,131]}$ 、减压渣油的加氢裂化 ${ }^{[132]}$ 和 CO 甲烷化反 
应 ${ }^{[133]}$, 甚至作为制备 $\mathrm{Co}_{3} \mathrm{O}_{4}$ 的祄底参与水裂解的研究 也有报道 ${ }^{[134]}$.

\section{5 总结与展望}

过渡金属硫族化合物纳米材料具有独特的二维结 构和优良的电学、光学以及催化特性, 在诸多领域表现 出巨大的应用潜力. 但目前的研究主要集中在 $\mathrm{MoS}_{2}$, 对其他 TMDCs 的结构与性能探索明显关注不够. 即使 对 $\mathrm{MoS}_{2}$ 的研究已取得了一定成果, 但仍有一些需要解 决的问题.

首先是材料的制备方法和工艺方面. 制备方法的难 易程度、产量以及对材料性质的影响都是评价制备方法 的依据. 目前采用较多的制备 TMDCs 纳米材料的方法 主要有机械剥离法、水(溶剂)热合成法和化学气相沉积 法. 其中机械剥离虽然不会改变材料本身的特性, 但产 量过低，且无法控制产物的尺寸以及厚度; 水(溶剂)热 法不仅可以用于合成单组分物质, 也可以用于复合材料 的制备, 但是该过程的影响因素多, 产物尺寸和厚度难 以控制, 尤其是难以合成高结晶度的产品; 化学气相沉 积法可以实现高质量 TMDCs 的批量制备, 但相对于前 两种方法, 其适用性相对较窄, 还有待于进一步推广. 由此可见, 制备技术仍是影响和制约 TMDCs 发展的重 要因素, 寻求更为有效的手段是今后研究的主要方向.

其次是材料的应用性能方面. TMDCs 在场效应晶 体管、逻辑电路、传感器、微波吸收和催化等领域都有 重要应用. TMDCs 具有合适的带隙宽度, 可以实现电子 器件的逻辑开关功能, 但是电子迁移率低是其固有的属 性. 与石墨烯等材料复合是对 TMDCs 的重要改性方法, 但复合材料的性能还有待进一步开发. 带隙可调是 TMDCs 最大的优点之一, 通过调整合适带隙宽度来构 建的光电探测器可以与不同波段的光耦合, 提高响应 度, 同时 TMDCs 还可以作为太阳能电池材料, 用于构 建超薄 PV 器件, 但是其 PCE 效率尚无法与传统材料相 比. 利用 TMDCs 构建传感器可以用于气体、湿度、生 物分子的高灵敏度检测，甚至可以间接测量金属离子, 但是对于一些物质的检测, 尤其是气体分子, 检测分子 的特异性识别仍然存在许多问题, 制约了其实际应用. 将 TMDCs 用于微波吸收材料是近几年出现的研究方向, 与传统材料相比, 单组分的 $\mathrm{MoS}_{2}$ 就能表现出优异的吸 波性能, 但是该领域的研究才刚起步, 吸波机理及成 分、形貌对性能的影响规律尚不十分明确. 当然, TMDCs 在储能器件和催化方面的研究也待深入.

总而言之, 高性能的 TMDCs 材料及应用研究任重 而道远. 但机遇与挑战并存, 相信随着理论研究和实践 的深入, 阻碍 TMDCs 发展的障碍将被慢慢移除, 新的 性能将被发掘，TMDCs 将以其独特的性质而得到更广 泛的应用.
作者简介

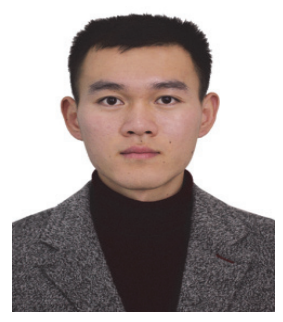

林潇羽, 男, 国防科技大学在读硕士研究生, 主要从事过 渡金属硫族化合物方面的研究.

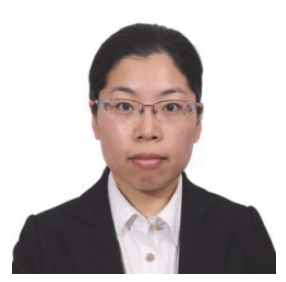

王璟, 女, 博士，副教授、硕士生导师，2009 年获国防科 技大学工学博士学位, 主要从事二维纳米材料的构建及超快 光化学反应研究. 主持国家自然科学基金项目 1 项, 教育部博 士点基金项目 1 项.

\section{References}

[1] Novoselov, K. S.; Geim, A. K.; Morozov, S. V.; Jiang, D.; Zhang, Y.; Dubonos, S. V.; Grigorieva, I. V.; Firsov, A. A. Science 2004, 306 , 666.

[2] Nag, A.; Raidongia, K.; Hembram, K. P. S. S.; Datta, R.; Waghmare, U. V.; Rao, C. N. R. ACS Nano 2010, 4, 1539.

[3] Behzad, S. Solid State Commun. 2016, 248, 27.

[4] Wang, Z. G.; Su, Q. L.; Yin, G. Q.; Shi, J. J.; Deng, H. Q.; Guan, J.; Wu, M. P.; Zhou, Y. L.; Lou, H. L.; Fu, Y. Q. Mater. Chem. Phys. 2014, 147, 1068 .

[5] Tan, C. L.; Zhang, H. Chem. Soc. Rev. 2015, 44, 2713.

[6] Cui, X. H.; Chen, H. Y.; Yang, T. Acta Chim. Sinica 2016, 74, 392. (崔向红, 陈怀银, 杨涛, 化学学报, 2016, 74, 392.)

[7] Poizot, P.; Laruelle, S.; Grugeon, S.; Dupont, L.; Tarascon, J.-M. Nature 2000, 407, 496.

[8] Naguib, M.; Mashtalir, O.; Carle, V.; Presser, V.; Hultman, L.; Gogotsi, Y.; Barsoum, M. W. ACS Nano 2012, 6, 1322.

[9] Anasori, B.; Lukatskaya, M. R.; Gogotsi, Y. Nat. Rev. Mater. 2017, 2, 16098 .

[10] Li, L. K.; Yu, Y. J.; Ye, G. J.; Ge, Q. Q.; Ou, X. D.; Wu, H.; Feng, D. L.; Chen, X. H.; Zhang, Y. D. Nat. Nanotechnol. 2014, 9, 372.

[11] Liu, H.; Du, Y. C.; Deng, Y. X.; Ye, P. D. Chem. Soc. Rev. 2015, 44, 2732.

[12] Song, J.; Wang, J.; Lin, X. Y.; He, J. F.; Liu, H. L.; Lei, Y. P.; Chu, Z. Y. ChemElectroChem 2017, 4, 2373.

[13] Marseglia, E. A. Int. Rev. Phys. Chem. 1983, 3, 177.

[14] Radisavljevic, B.; Radenovic, A.; Brivio, J.; Giacometti, V.; Kis, A. Nat. Nanotechnol. 2011, 6, 147.

[15] Wang, Q. H.; Kalantar-Zadeh, K.; Kis, A.; Coleman, J. N.; Strano, M. S. Nat. Nanotechnol. 2012, 7, 699.

[16] Chhowalla, M.; Shin, H. S.; Eda, G.; Li, L. J.; Loh, K. P.; Zhang, H. Nat. Chem. 2013, 5, 263.

[17] Klein, A.; Tiefenbacher, S.; Eyert, V.; Pettenkofer, C.; Jaegermann, W. Phys. Rev. B 2001, 64, 205416.

[18] Tongay, S.; Zhou, J.; Ataca, C.; Lo, K.; Matthews, T. S.; Li, J.; Grossman, J. C.; Wu, J. Nano Lett. 2012, 12, 5576.

[19] Lee, C.; Yan, H. G.; Brus, L. E.; Heinz, T. F.; Hone, J.; Ryu, S. ACS Nano 2010, 4, 2695.

[20] Novoselov, K. S.; Jiang, D.; Schedin, F.; Booth, T. J.; Khotkevich, V. V.; Morozov, S. V.; Geim, A. K. J. Am. Chem. Soc. 2005, 102, 10451 . 
[21] Li, H.; Yin, Z. Y.; He, Q.; Li, H.; Huang, X.; Lu, G.; Fam, D. W. H.; Tok, A. I. Y.; Zhang, Q.; Zhang, H. Small 2012, 8, 63.

[22] Hernandez, Y.; Nicolosi, V.; Lotya, M.; Blighe, F. M.; Sun, Z. Y.; De, S.; McGovern, I. T.; Holland, B.; Byrne, M.; Gun'Ko, Y. K.; Boland, J. J.; Niraj, P.; Duesberg, G.; Krishnamurthy, S.; Goodhue, R.; Hutchison, J.; Scardaci, V.; Ferrari, A. C.; Coleman, J. N. Nat. Nanotechnol. 2008, 3, 563.

[23] Coleman, J. N.; Lotya, M.; O'Neill, A.; Bergin, S. D.; King, P. J.; Khan, U.; Young, K.; Gaucher, A.; De, S.; Smith, R. J.; Shvets, I. V.; Arora, S. K.; Stanton, G.; Kim, H. Y.; Lee, K.; Kim, G. T.; Duesberg, G. S.; Hallam, T.; Boland, J. J.; Wang, J. J.; Donegan, J. F.; Grunlan, J. C.; Moriarty, G.; Shmeliov, A.; Nicholls, R. J.; Perkins, J. M.; Grieveson, E. M.; Theuwissen, K.; McComb, D. W.; Nellist, P. D.; Nicolosi, V. Science 2011, 331, 568.

[24] Nicolosi, V.; Chhowalla, M.; Kanatzidis, M. G.; Strano, M. S.; Coleman, J. N. Science 2013, 340, 1226419.

[25] Wang, K. P.; Wang, J.; Fan, J. T.; Lotya, M.; O'Neill, A.; Fox, D.; Feng, Y. Y.; Zhang, X. Y.; Jiang, B. X.; Zhao, Q. Z.; Zhang, H. Z.; Coleman, J. N.; Zhang, L.; Blau, W. J. ACS Nano 2013, 7, 9260.

[26] Smith, R. J.; King, P. J.; Lotya, M.; Wirtz, C.; Khan, U.; De, S.; O'Neill, A.; Duesberg, G. S.; Grunlan, J. C.; Moriarty, G.; Chen, J.; Wang, J.; Minett, A. I.; Nicolosi, V.; Coleman, J. N. Adv. Mater. 2011, 23, 3944.

[27] Joensen, P. F. R. F.; Morrison, S. R. Mater. Res. Bull. 1986, 21, 457.

[28] Matte, H. S. S. R.; Gomathi, A.; Manna, A. K.; Late, D. J.; Datta, R.; Pati, S. K.; Rao, C. N. R. Angew. Chem. 2010, 122, 4153.

[29] Eda, G.; Yamaguchi, H.; Voiry, D.; Fujita, T.; Chen, M.; Chhowalla, M. Nano Lett. 2011, 11, 5111.

[30] Zeng, Z. Y.; Yin, Z. Y.; Huang, X.; Li, H.; He, Q. Y.; Lu, G.; Boey, F.; Zhang, H. Angew. Chem., Int. Ed. 2011, 50, 11093.

[31] Zeng, Z. Y.; Sun, T.; Zhu, J. X.; Huang, X.; Yin, Z. Y.; Lu, G.; Fan, Z. X.; Yan, Q. Y.; Hng, H. H.; Zhang, H. Angew. Chem. 2012, 51, 9052.

[32] Peng, Y. Y.; Meng, Z. Y.; Zhong, C.; Lu, J.; Yu, W. C.; Jia, Y. B.; Qian, Y. T. Chem. Lett. 2001, 8, 772.

[33] Peng, Y. Y.; Meng, Z. Y.; Zhong, C.; Lu, J.; Yu, W. C.; Yang, Z. P.; Qian, Y. T. J. Solid State Chem. 2001, 159, 170.

[34] He, H. Y. Res. Chem. Intermed. 2010, 36, 155.

[35] Zhang, X. H.; Yang, X. H.; Yang, F.; Xue, M. Q.; Luo, G. S. Micro Nano Lett. 2015, 10, 339 .

[36] Chakravarty, D.; Late, D. J. RSC Adv. 2015, 5, 21700.

[37] Wu, J. F.; Fu, X. Mater. Lett. 2007, 61, 4332.

[38] Cao, S. X.; Liu, T. M.; Zeng, W.; Hussain, S.; Peng, X. H.; Pan, F. S. J. Mater. Sci.: Mater. Electron. 2014, 25, 4300.

[39] Cao, S. X.; Liu, T. M.; Hussain, S.; Zeng, W.; Peng, X. H.; Pan, F. S. Mater. Lett. 2014, 129, 205.

[40] Huang, G. C.; Chen, T.; Chen, W. X.; Wang, Z.; Chang, K.; Ma, L.; Huang, F. H.; Chen, D. Y.; Lee, J. Y. Small 2013, 9, 3693.

[41] Shelke, N. T.; Karche, B. R. J. Alloys Compd. 2015, 653, 298.

[42] Li, H. Y.; Chen, S. M.; Jia, X. F.; Xu, B.; Lin, H. F.; Yang, H. Z.; Song, L.; Wang, X. Nat. Commun. 2017, 8, 15377.

[43] Lee, Y. H.; Zhang, X. Q.; Zhang, W. J.; Chang, M. T.; Lin, C. T.; Chang, K. D.; Yu, Y. C.; Wang, J. T. W.; Chang, C. S.; Li, L. J.; Lin, T. W. Adv. Mater. 2012, 24, 2320.

[44] Elías, A. L.; Perea-López, N.; Castro-Beltrán, A.; Berkdemir, A.; Lv, R. T.; Feng, S. M.; Long, A. D.; Hayashi, T.; Kim, Y. A.; Endo, M.; Gutiérrez, H. R.; Pradhan, N. R.; Balicas, L.; Mallouk, T. E.; López-Urías, F.; Terrones, H.; Terrones, M. ACS Nano 2013, 7, 5235.

[45] Lin, Y. C.; Zhang, W. J.; Huang, J. K.; Liu, K. K.; Lee, Y. H.; Liang, C. T.; Chu, C. W.; Li, L. J. Nanoscale 2012, 4, 6637.

[46] Zhan, Y. J.; Liu, Z.; Najmaei, S.; Ajayan, P. M.; Lou, J. Small 2012, 8, 966.

[47] Laskar, M. R.; Ma, L.; Kannappan, S.; Park, P. S.; Krishnamoorthy, S.; Nath, D. N.; Lu, W.; Wu, Y. Y.; Rajan, S. Appl. Phys. Lett. 2013, $102,252108$.

[48] Najmaei, S.; Liu, Z.; Zhou, W.; Zou, X. L.; Shi, G.; Lei, S. D.; Yakobson, B. I.; Idrobo, J. C.; Ajayan, P. M.; Lou, J. Nat. Mater. 2013, $12,754$.

[49] Lee, Y. H.; Yu, L.; Wang, H.; Fang, W.; Ling, X.; Shi, Y.; Lin, C. T.; Huang, J. K.; Chang, M. T.; Chang, C. S.; Dresselhaus, M.; Palacios, T.; Li, L. J.; Kong, J. Nano Lett. 2013, 13, 1852.

[50] Shi, J. P.; Ma, D. L.; Zhang, Y. F.; Liu, Z. F. Acta Chim. Sinica 2015, 73, 877. (史建平, 马东林, 张艳锋, 刘忠范, 化学学报, 2015, 73, 877.)

[51] Wang, B. B.; Zheng, K.; Zhong, X. X.; Gao, D.; Gao, B. J. Alloys
Compd. 2017, 695, 27.

[52] Xu, G. C.; Lu, Z. X.; Zhang, Q.; Qiu, H. L.; Jiao, L. Y. Acta Chim. Sinica 2015, 73, 895. (许冠辰, 卢至行, 张琪, 邱海龙, 焦丽颖, 化学学报, 2015, 73, 895.)

[53] Mahler, B.; Hoepfner, V.; Liao, K.; Ozin, G. J. Am. Chem. Soc. 2014, 136,14121 .

[54] Jung, W.; Lee, S.; Yoo, D.; Jeong, S.; Miro, P.; Kuc, A.; Heine, T.; Cheon, J. J. Am. Chem. Soc. 2015, 137, 7266.

[55] Guo, W. B.; Chen, Y. Z.; Wang, L. S.; Xu, J.; Zeng, D. Q.; Peng, D. L. Electrochim. Acta 2017, 231, 69.

[56] Huang, X.; Yin, Z. Y.; Wu, S. X.; Qi, X. Y.; He, Q. Y.; Zhang, Q. C.; Yan, Q. Y.; Boey, F.; Zhang, H. Small 2011, 7, 1876.

[57] Han, M. Y.; Ozyilmaz, B.; Zhang, Y.; Kim, P. Phys. Rev. Lett. 2007, 98, 206805.

[58] Zhang, Y.; Tang, T. T.; Girit, C.; Hao, Z.; Martin, M. C.; Zettl, A.; Crommie, M. F.; Shen, Y. R.; Wang, F. Nature 2009, 459, 820.

[59] Chen, F.; Xia, J. L.; Ferry, D. K.; Tao, N. J. Nano Lett. 2009, 9, 2571.

[60] Konar, A.; Fang, T.; Jena, D. Phys. Rev. B 2010, 82, 115452.

[61] Li, X. L.; Wang, X. R.; Zhang, L.; Lee, S.; Dai, H. J. Science 2008, 319, 1229.

[62] Gomez, L.; Aberg, I.; Hoyt, J. L. IEEE Electron Dev. Lett. 2007, 28 , 285.

[63] Kim, S. Y.; Park, S.; Choi, W. Appl. Phys. Lett. 2016, 109, 152101.

[64] Guo, J.; Jiang, J.; Zheng, Z.; Yang, B. Org. Electron. 2017, 40, 75.

[65] Yoon, Y.; Ganapathi, K.; Salahuddin, S. Nano Lett. 2011, 11, 3768.

[66] Ovchinnikov, D.; Allain, A.; Huang, Y. S.; Dumcenco, D.; Kis, A. ACS Nano 2014, 8, 8174 .

[67] Kwak, J. Y.; Hwang, J.; Calderon, B.; Alsalman, H.; Munoz, N.; Schutter, B.; Spencer, M. G. Nano Lett. 2014, 14, 4511.

[68] Srivastava, A.; Fahad, M. S. Solid-State Electron. 2016, 126, 96.

[69] Radisavljevic, B.; Whitwick, M. B.; Kis, A. ACS Nano 2011, 5, 9934.

[70] Zou, X.; Huang, C. W.; Wang, L.; Yin, L. J.; Li, W.; Wang, J.; Wu, B.; Liu, Y.; Yao, Q.; Jiang, C.; Wu, W. W.; He, L.; Chen, S.; Ho, J. C.; Liao, L. Adv. Mater. 2016, 28, 2062.

[71] Lee, H. S.; Min, S. W.; Chang, Y. G.; Park, M. K.; Nam, T.; Kim, H.; Kim, J. H.; Ryu, S.; Im, S. Nano Lett. 2012, 12, 3695.

[72] Wang, X. D.; Wang, P.; Wang, J. L.; Hu, W. D.; Zhou, X. H.; Guo, N.; Huang, H.; Sun, S.; Shen, H.; Lin, T.; Tang, M. H.; Liao, L.; Jiang, A. Q.; Sun, J. L.; Meng, X. J.; Chen, X. S.; Lu, W.; Chu, J. H. Adv. Mater. 2015, 27, 6575.

[73] Xie, Y.; Zhang, B.; Wang, S. X.; Wang, D.; Wang, A. Z.; Wang, Z. Y.; Yu, H. H.; Zhang, H. J.; Chen, Y. X.; Zhao, M. W.; Huang, B. B.; Mei, L. M.; Wang, J. Y. Adv. Mater. 2017, 29, 1605972.

[74] Chang, Y. H.; Zhang, W. J.; Zhu, Y. H.; Han, Y.; Pu, J.; Chang, J. K.; Hsu, W. T.; Huang, J. K.; Hsu, C. L.; Chi, M. H.; Takenobu, T.; Li, H. N.; Wu, C. I.; Chang, W. H.; Wee, A. T. S.; Li, L. J. ACS Nano 2014, 8, 8582.

[75] Bernardi, M.; Palummo, M.; Grossman, J. C. Nano Lett. 2013, 13, 3664.

[76] Ma, C. Y.; Fu, W. F.; Huang, G. W.; Chen, H. Z.; Xu, M. S. Acta Chim. Sinica 2015, 73, 949. (马春燕, 傅伟飞, 黄国伟, 陈红征, 徐明生, 化学学报, 2015, 73, 949.)

[77] Tsai, M. L.; Su, S. H.; Chang, J. K.; Tsai, D. S.; Chen, C. H.; Wu, C. I.; Li, L. J.; Chen, L. J.; He, J. H. ACS Nano 2014, 8, 8317.

[78] Deng, Q. R.; Li, Y. Q.; Shen, Y. L.; Chen, L.; Wang, G. M.; Wang, S. G. Mod. Phys. Lett. B 2017, 31, 1750079.

[79] Reynolds, K. J.; Barker, J. A.; Greenham, N. C.; Friend, R. H.; Frey, G. L. J. Appl. Phys. 2002, 92, 7556.

[80] Liu, J.; Zeng, Z.; Cao, X.; Lu, G.; Wang, L. H.; Fan, Q. L.; Huang, W.; Zhang, H. Small 2012, 8, 3517.

[81] Afzal, A.; Cioffi, N.; Sabbatini, L.; Torsi, L. Sens. Actuators B 2012, 171-172, 25.

[82] Late, D. J.; Doneux, T.; Bougouma, M. Appl. Phys. Lett. 2014, 105, 233103.

[83] Li, X. G.; Li, X. X.; Li, Z.; Wang, J.; Zhang, J. W. Sens. Actuators B 2017, 240, 273.

[84] Donarelli, M.; Prezioso, S.; Perrozzi, F.; Bisti, F.; Nardone, M.; Giancaterini, L.; Cantalini, C.; Ottaviano, L. Sens. Actuators B 2015, 207, 602 .

[85] Luo, Y. H.; Chen, C. Y.; Xia, K.; Peng, S. H.; Guan, H. Y.; Tang, J. Y.; Lu, H. U.; Yu, J. H.; Zhang, J.; Xiao, Y.; Chen, Z. Opt. Express 2016, 24, 8956 .

[86] He, S. J.; Song, B.; Li, D.; Zhu, C. F.; Qi, W. P.; Wen, Y. Q.; Wang, L. H.; Song, S. P.; Fang, H. P.; Fan, C. H. Adv. Func. Mater. 2010, 
$20,453$.

[87] Baby, T. T.; Aravind, S. S. J.; Arockiadoss, T.; Rakhi, R. B.; Ramaprabhu, S. Sens. Actuators B 2010, 145, 71.

[88] Liu, Y. X.; Dong, X. C.; Chen, P. Chem. Soc. Rev. 2012, 41, 2283.

[89] Zhu, C. F.; Zeng, Z. Y.; Li, H.; Li, F.; Fan, C. H.; Zhang, H. J. Am. Chem. Soc. 2013, 135, 5998.

[90] Jin, K.; Xie, L. M.; Tian, Y.; Liu, D. M. J. Phys. Chem. C 2016, 120, 11204.

[91] Xiang, X.; Shi, J. B.; Huang, F. H.; Zheng, M. M.; Deng, Q. C.; Xu, J. Q. Biosens. Bioelectron. 2015, 74, 227.

[92] Xi, Q.; Zhou, D. M.; Kan, Y. Y.; Ge, J.; Wu, Z. K.; Yu, R. Q.; Jiang, J. H. Anal. Chem. 2014, 86, 1361 .

[93] Wang, X. X.; Nan, F. X.; Zhao, J. L.; Yang, T.; Ge, T.; Jiao, K. Biosens. Bioelectron. 2015, 64, 386.

[94] Yang, Y. Y.; Zhang, H.; Huang, C. S.; Yang, D. P.; Jia, N. Q. Biosens. Bioelectron. 2017, 89, 461 .

[95] Ning, M. Q.; Lu, M. M.; Li, J. B.; Chen, Z.; Dou, Y. K.; Wang, C. Z.; Rehman, F.; Cao, M. S.; Jin, H. B. Nanoscale 2015, 7, 15734.

[96] Liang, X. H.; Zhang, X. M.; Liu, W.; Tang, D. M.; Zhang, B. S.; Ji, G. B. J. Mater. Chem. C 2016, 4, 6816

[97] Zhang, X. J.; Li, S.; Wang, S. W.; Yin, Z. J.; Zhu, J. Q.; Guo, A. P.; Wang, G. S.; Yin, P. G.; Guo, L. J. Phys. Chem. C 2016, 120, 22019.

[98] Ding, X.; Huang, Y.; Li, S. P.; Zhang, N.; Wang, J. G. Composites Part $A$ 2016, 90, 424

[99] Zhang, X. J.; Wang, S. W.; Wang, G. S.; Li, Z.; Guo, A. P.; Zhu, J. Q.; Liu, D. P.; Yin, P. G. RSC Adv. 2017, 7, 22454

[100] Palacin, M. R. Chem. Soc. Rev. 2009, 38, 2565.

[101] Guo, G. H.; Hong, J. H.; Cong, C. J.; Zhou, X. W. J. Mater. Sci. 2005, 40, 2557.

[102] Du, G. D.; Guo, Z. P.; Wang, S. Q.; Zeng, R.; Chen, Z. X.; Liu, H. K. Chem. Commun. 2010, 46, 1106

[103] Wang, P. P.; Sun, H.; Ji, Y.; Li, W.; Wang, X. Adv. Mater. 2014, 26, 964.

[104] Zhou, L. Y.; Yan, S. C.; Pan, L. J.; Wang, X. R.; Wang, Y. Q.; Shi, Y. Nano Res. 2016, 9, 857.

[105] Seng, K. H.; Du, G. D.; Li, L.; Chen, Z. X.; Liu, H. K.; Guo, Z. P. J. Mater. Chem. 2012, 22, 16072.

[106] Cao, Y.; Lin, X. G.; Zhang, C. L.; Yang, C.; Zhang, Q.; Hu, W. Q.; Zheng, M. S.; Dong, Q. F. RSC Adv. 2014, 4, 30150

[107] Chang, K.; Chen, W. X. ACS Nano 2011, 5, 4720.

[108] Luo, Z. G.; Zhou, J.; Wang, L. R.; Fang, G. Z.; Pan, A. Q.; Liang, S. Q. J.Mater. Chem. A 2016, 4, 15302 .

[109] Wang, J. Y.; Zhao, X. M.; Fu, Y. S.; Wang, X. Appl. Surf. Sci. 2017, 399, 237.

[110] Soon, J. M.; Loh, K. P. Electrochem. Solid-State Lett. 2007, 10, 250.

[111] Zhou, J.; Fang, G. Z.; Pan, A. Q.; Liang, S. Q. ACS Appl. Mater. Interfaces 2016, 8,33681 .
[112] Zheng, N. F.; Bu, X. H.; Feng, P. Y. Nature 2003, 426, 428.

[113] Xiao, J.; Choi, D.; Cosimbescu, L.; Koech, P.; Liu, J.; Lemmon, J. P. Chem. Mater. 2010, 22.

[114] Wang, J.; Wu, Z. C.; Hu, K. H.; Chen, X. Y.; Yin, H. B. J. Alloys Compd. 2015, 619, 38.

[115] Nørskov, J. K.; Bligaard, T.; Rossmeisl, J.; Christensen, C. H. Nat. Chem. 2009, 1, 37.

[116] Hinnemann, B.; Moses, P. G.; Bonde, J.; Jorgensen, K. P.; Nielsen, J. H.; Horch, S.; Chorkendorff, I.; Nørskov, J. K. J. Am. Chem. Soc 2005, 127, 5308 .

[117] Li, Y. G.; Wang, H. L.; Xie, L. M.; Liang, Y. Y.; Hong, G. S.; Dai, H. J. J. Am. Chem. Soc. 2011, 133, 7296.

[118] Li, T. S.; Galli, G. J. Phys. Chem. C 2007, 111, 16192.

[119] Tsai, C.; Chan, K.; Abild-Pedersen, F.; Nørskov, J. K. Phys. Chem. Chem. Phys. 2014, 16, 13156.

[120] Jaramillo, T. F.; Jorgensen, K. P.; Bonde, J.; Nielsen, J. H.; Horch, S.; Chorkendorff, I. Science 2007, 317, 100.

[121] Skulason, E.; Karlberg, G. S.; Rossmeisl, J.; Bligaard, T.; Greeley, J.; Jonsson, H.; Norskov, J. K. Phys. Chem. Chem. Phys. 2007, 9, 3241.

[122] Xu, X. B.; Sun, Y.; Qiao, W.; Zhang, X.; Chen, X.; Song, X. Y.; Wu, L. Q.; Zhong, W.; Du, Y. W. Appl. Surf. Sci. 2017, 396, 1520.

[123] Wang, X. Q.; Chen, Y. F.; Zheng, B. J.; Qi, F.; He, J. R.; Li, Q.; Li, P J.; Zhang, W. L. J. Alloys Compd. 2017, 691, 698.

[124] Chen, Z.; Cummins, D.; Reinecke, B. N.; Clark, E.; Sunkara, M. K.; Jaramillo, T. F. Nano Lett. 2011, 11, 4168.

[125] Yang, Y.; Wang, S. T.; Zhang, J. C.; Li, H. Y.; Tang, Z. L.; Wang, X. Inorg. Chem. Front. 2015, 2, 931.

[126] Ding, J. B.; Zhou, Y.; Li, Y. G.; Guo, S. J.; Huang, X. Q. Chem. Mater. 2016, 28, 2074

[127] Lukowski, M. A.; Daniel, A. S.; Meng, F.; Forticaux, A.; Li, L.; Jin S. J. Am. Chem. Soc. 2013, 135, 10274.

[128] Voiry, D.; Salehi, M.; Silva, R.; Fujita, T.; Chen, M.; Asefa, T.; Shenoy, V. B.; Eda, G.; Chhowalla, M. Nano Lett. 2013, 13, 6222.

[129] Wang, D. Z.; Zhang, X. Y.; Bao, S. Y.; Zhang, Z. T.; Fei, H.; Wu, Z. Z. J. Mater. Chem. A 2017, 5, 2681.

[130] Lauritsen, J. V.; Nyberg, M.; Nørskov, J. K.; Clausen, B. S.; Topsøe, H.; Lægsgaard, E.; Besenbacher, F. J. Catal. 2004, 224, 94.

[131] Tsverin, Y.; Popovitz-Biro, R.; Feldman, Y.; Tenne, R.; Komarneni, M. R.; Yu, Z. Q.; Chakradhar, A.; Sand, A.; Burghaus, U. Mater. Res. Bull. 2012, 47, 1653 .

[132] Hur, Y. G.; Kim, M. S.; Lee, D. W.; Kim, S.; Eom, H. J.; Jeong, G.; No, M. H.; Nho, N. S.; Lee, K. Y. Fuel 2014, 137, 237.

[133] Zhang, C. Y.; Liu, B. N.; Wang, Y. X.; Zhao, L.; Zhang, J.; Zong, Q. Y.; Gao, J. S.; Xu, C. M. RSC Adv. 2017, 7, 11862.

[134] Wang, X. D.; Zheng, Y. Y.; Yuan, J. H.; Shen, J. F.; Wang, A. J.; Niu, L.; Huang, S. T. Electrochim. Acta 2016, 212, 890. 